\title{
La influencia del cambio climático en el acceso y aprovisionamiento de granos básicos
}

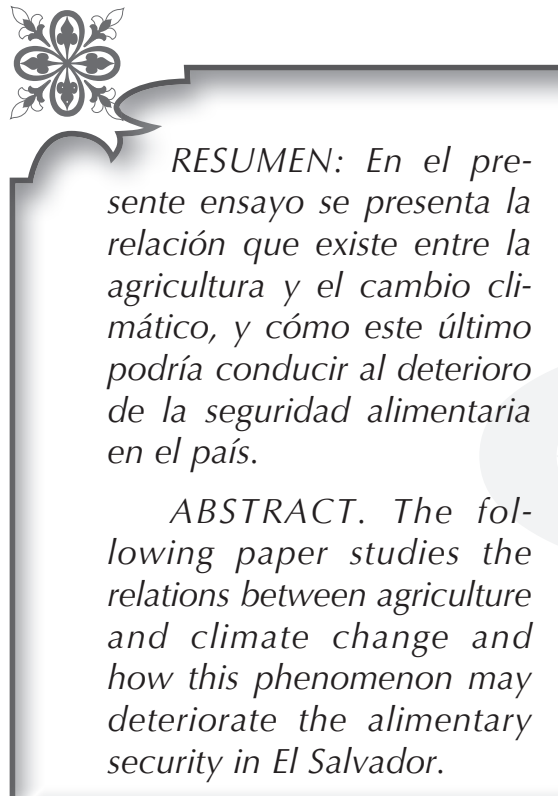

Mauricio Iraheta Cintya Molina José Fermín Villatoro

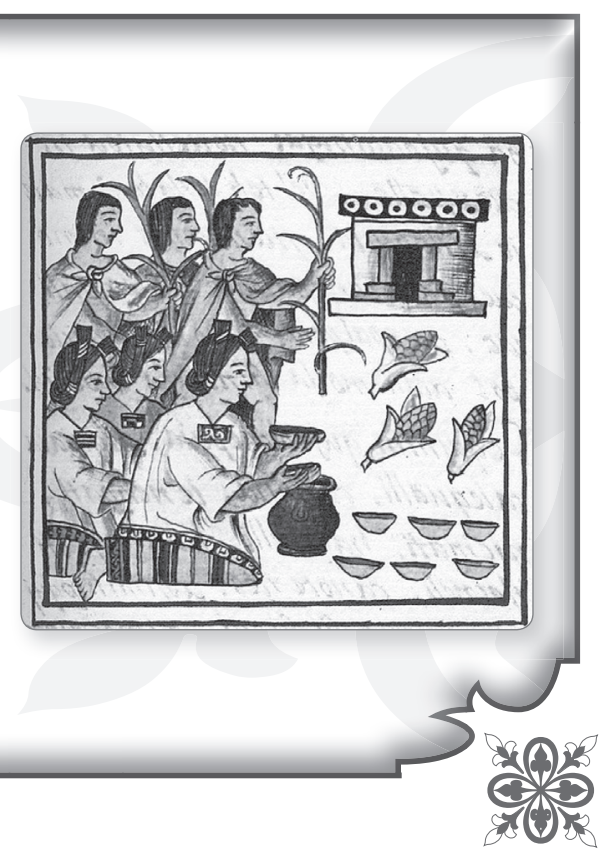

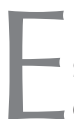
I objetivo de este texto es presentar la relación que existe entre la concepción de desarrollo, el estilo de crecimiento y el cambio climático. Posteriormente, se intenta presentar la relación que existe entre la agricultura y el cambio climático, y cómo este último podría reducir, en el país, la capacidad de la agricultura para producir alimentos y tener como consecuencia final el deterioro de la seguridad alimentaria.
En la segunda parte del trabajo se presentan de forma resumida los esfuerzos que desde la comunidad nacional e internacional se han realizado para hacerle frente al cambio climático y sus manifestaciones. Con esto se intenta demostrar que el estudio de las consecuencias del cambio climático representa un reto y una necesidad para los economistas en la actualidad. 


\section{을 I.La economía detrás del cambio climático}

\subsection{Las implicaciones del desarro- llo económico}

El concepto de desarrollo ha estado presente en la sociedad desde sus inicios, sin embargo, ha ido evolucionando. En un principio, el desarrollo estaba asociado a la riqueza de una nación, de hecho, la riqueza y la forma de generarla se convirtieron en los objetos principales de estudio para muchos pensadores, entre ellos Adam Smith.

Según Adam Smith, existen cinco factores que contribuyen a la riqueza de una nación: el clima, la calidad de la tierra, la extensión territorial, la productividad del trabajo, y la relación entre trabajo productivo y no productivo (Smith, 1776). Las ideas del economista inglés, especialmente las relacionadas al trabajo y la productividad, contribuyeron para la comprensión de la economía capitalista. Sin embargo, hubo un distanciamiento en el desarrollo de los otros tres factores que fue empujado por la expansión de la industrialización.

El modelo de industrialización que nació en Europa en 1750 - y que posteriormente alcanzó a países como Estados Unidos y Japóncambió la dinámica económica mundial. El desarrollo técnico transformó los procesos de producción, mecanizándolos, traduciéndose en una mayor eficiencia en la utilización de los recursos. Esto generó una mayor productividad y permitió una mejora en la calidad de vida de la población, un hecho sin precedentes para una sociedad que no había experimentado cambios significativos en su calidad de vida en los últimos 250 años (Martínez, 2007).

El desarrollo de procesos industriales permitió a muchos países que no contaban con muchos recursos energéticos obtener una ventaja competitiva (Vidal Villa, 1996). Junto con la revolución y el auge industrial tuvo lugar una revolución agronómica que permitió incrementar la oferta mundial de alimentos, lo que trajo como consecuencia un aumento sostenido en la tasa de crecimiento de la población (Vidal Villa, 1996). El incremento en la población y el grado de desarrollo industrial dio lugar a un proceso de "urbanización" de la población. Con el pasar de los años, cada vez menos personas vivían en las áreas rurales y las ciudades demandaban mayor espacio y energía para poder acoger a su creciente población.

Los países en los que se implementaron procesos industrializadores sufrieron más el fenómeno de la migración a las ciudades que aquellos que no habían adoptado el modelo industrial. La migración a las ciudades obedecía en parte a los mejores ingresos que generaban las industrias en comparación con lo que se generaba en las labores agrícolas. El incremento en los ingresos urbanos generó una mayor demanda de productos y servicios, 
que al mismo tiempo elevó la demanda energética de los países industrializados.

Desde principios del siglo XIX hasta mediados del siglo $X X$, se produjo un aumento en el consumo de energía, este aumento, no significaba un problema para las economías que se encontraban en constante crecimiento. El perfeccionamiento de las tecnologías y el descubrimiento de nuevas fuentes de energía como el petróleo y el gas natural, compensaban los aumentos en el consumo. Estos combustibles que en un momento sirvieron exclusivamente a la industria comenzaron a introducirse en las viviendas urbanas permitiendo importantes mejoras en la economía y en la sociedad en general.

Se produjo una brecha entre la forma de vida de los habitantes de los países industrializados y los habitantes de aquellos países que no habían adoptado el modelo de industrialización. La diferencia en el grado de avance tecnológico y social entre países, propiciaron la construcción de los conceptos de países desarrollados y países en vías de desarrollo. En los países desarroIlados ha existido un crecimiento sostenido de la capacidad productiva distribuida entre las diversas ramas de actividad económica. El progreso tecnológico se amplía en todos los niveles y direcciones logrando homogeneidad, además, la población tiene un porcentaje mínimo de participación en el sector agrícola y los procesos que se ejecutan en éste, están altamente mecanizados. A diferencia de los países desarrollados, los países en vías de desarrollo han tenido una estructura productiva sostenida en actividades primario-exportadoras, un sector agrícola de baja productividad y la capacidad adquisitiva de sus habitantes no permite diversificar su estructura de consumo.

Avanzado el siglo $\mathrm{XX}$, la tercera revolución industrial, permitió la consolidación total del modelo industrial e hizo más evidentes las diferencias entre países. Entonces, con el objetivo de reducir la brecha entre países desarrollados y en vías de desarrollo se adoptó un proceso de industrialización de las economías de los países en vías de desarrollo. En gran parte de América Latina, por ejemplo, se implementó un modelo de Industrialización por Sustitución de Importaciones (ISI), el cual ha sido muy estudiado debido a los logros obtenidos, pero principalmente debido a sus desaciertos.

Independientemente de las razones que motivaron el éxito o fracaso de los modelos de industrialización implementados en los países en vías de desarrollo, la realidad es que el cambio en el modelo de crecimiento impactó seriamente el consumo energético a nivel mundial. Lo anterior fue posible debido a que los pocos o muchos ingresos obtenidos en los países en vías de desarrollo se utilizaron para comprar vehículos, maquinarias y otra serie de artefactos que consumían cada vez más energía. 
El creciente consumo de energía no fue percibido como un problema, de hecho, se ha utilizado como un indicador del avance o retroceso de una economía. Por otra parte, la introducción de tecnologías que mejorasen la calidad de vida de los habitantes de un país no debía ser un problema. Por lo tanto, el desarrollo de la industria se convirtió en el paradigma que permitiría a los países en vías de desarrollo alcanzar finalmente el desarrollo. La forma de vida de los países industrializados se convirtió en el modelo a seguir.

Lo anterior, no implica que la forma de vida de los países desarrollados deba ser condenada y que los países en vías de desarrollo deban seguir bajo un esquema de vida prehistórico, lo que se intenta demostrar es cómo la expansión del Modelo Industrial es la principal responsable del aumento en el consumo mundial de energía que ocurrió entre el siglo XVIII y el siglo XX. Además, el aumento en dicho consumo no es el problema principal, sino mas bien las fuentes de donde se obtiene la energía.

Desde el inicio de la revolución industrial hasta el presente, la principal fuente de generación de energía han sido los combustibles fósiles. Inicialmente se utilizó el carbón, pero los avances en la exploración y utilización de recursos naturales permitieron que el petróleo se posicionara como la principal fuente de energía a nivel mundial.
Hay que destacar que la utilización de combustibles fósiles como principal fuente de generación de energía no es una casualidad, de hecho, obedece a factores económicos y tecnológicos bien definidos. En primer lugar, aún cuando el precio por MWh generado a partir de bunker y fuel oil, es relativamente alto comparado con el precio de un MWh generado a partir de una central hidroeléctrica, se ha preferido desarrollar centrales térmicas para generación eléctrica debido a que estas conllevan un volumen de inversión inicial más bajo y no se incurren en trámites de concesión con el Estado. Misma situación ocurre con la energía eólica, biomasa, solar fotovoltaica, solar térmica, etc. Que debido a que implican altos volúmenes de inversión inicial y muchos años de investigación previa antes de que dichos proyectos puedan desarrollarse han sido no totalmente descartadas pero sí con proyectos incipientes y aislados en muchos países, sobre todo en los que están en vías de desarrollo. En segundo lugar, la seguridad y la capacidad para generar energía que tienen estos combustibles es relativamente alta comparada con el resto, desde una perspectiva del corto plazo. Por lo tanto, con base en los criterios de maximización de beneficios y reducción de costos, hasta el momento, los combustibles fósiles han resultado ser la mejor alternativa para los inversores privados ${ }^{1}$. 
Sin embargo, la eficacia de los combustibles fósiles se ve disminuida si se incluyen los efectos adversos que se producen al utilizarse. En el proceso de combustión de un combustible; ya sea carbón, gas natural $u$ otro combustible derivado del petróleo, sus moléculas de Carbono $(\mathrm{C})$ entran en contacto con el Oxígeno $\left(\mathrm{O}_{2}\right)$ de la atmósfera. Esta interacción produce la oxidación y genera un gas conocido cómo Dióxido de Carbono $\left(\mathrm{CO}_{2}\right)$. Este gas se encuentra de forma natural en la atmósfera de la Tierra y es el principal responsable del Efecto Invernadero (Ver Recuadro 1.1), y es por ello que al $\mathrm{CO}_{2}$ se le denomina como un Gas de Efecto Invernadero (GEI). De hecho, el elevado consumo de combustibles fósiles ha convertido al $\mathrm{CO}_{2}$ en el principal Gas de Efecto Invernadero.

\subsection{Un efecto del desarrollo econó- mico: el cambio climático}

Como se ha desarrollado anteriormente la presencia de GEI en la atmósfera es natural y positiva para el desarrollo de la vida en la Tierra. Sin embargo, el crecimiento de la población y de los diferentes sectores de la actividad económica que intervienen en la generación de $\mathrm{GEI}^{2}$ ha elevado de forma alarmante la concentración de GEl en la atmósfera. Estos incrementos en las concentraciones de GEl alteran el equilibrio en el sistema climático ${ }^{3}$, el cual busca restablecer nuevamente el balance perdido respondiendo con ajustes como: calentamiento de la superficie terrestre, variaciones en las precipitaciones, cambio en la circulación atmosférica, incremento del nivel medio del mar, etc. Todas estas variaciones en los parámetros del clima, es lo que se denomina como Cambio Climático (MARN, 1998).

El cambio climático ha sido discutido ampliamente y actualmente la mayor parte de la comunidad científica lo acepta como un hecho irrefutable y de magnitud global. Sus efectos aún son inciertos. Sin embargo, el consenso general estima que las principales formas en las que se manifestará el cambio climático son las siguientes:

Cambios regionales y mundiales en la temperatura.

Alteración de las precipitaciones y el patrón lluvioso en muchas regiones.

Modificaciones en la presión atmosférica, la humedad, la velocidad y dirección del viento, el brillo solar y la nubosidad. (IPCC, 2007). 
Recuadro 1.1

¿Qué es el efecto envernadero?

La composición atmosférica de la tierra es la responsable del efecto invernadero. La atmósfera que recubre el planeta tiene cuatro funciones:

- Absorber la radiación emitida por el Sol.

- Reflejar la radiación solar absorbida.

- Captar la radiación solar reflejada por los gases invernaderos.

- Expulsar la radiación solar al espacio (González, 2008)

Para el año 1827, el matemático francés Jean B. J. Fourie había logrado demostrar la importancia de la atmósfera terrestre. Fourier comparaba la influencia de la atmósfera terrestre con un invernadero y afirmaba que los gases que formaban la atmósfera de la Tierra servían como paredes de cristal de un invernadero para mantener el calor (Lomelí, 2008).

Los avances científicos permitieron descomponer la atmósfera terrestre y estudiar más a profundidad su comportamiento. Se descubrió que la atmósfera está compuesta casi por completo por los siguientes elementos: oxígeno, nitrógeno, carbono y argón.

Si bien es cierto, éstos elementos se pueden encontra aislados en la atmósfera, generalmente se unen entre si para transformarse en gases como el dióxido de carbono $\left(\mathrm{CO}_{2}\right)$, el vapor de agua $\left(\mathrm{H}_{2} \mathrm{O}\right)$, el ozono $\left(\mathrm{O}_{3}\right)$, el metano $\left(\mathrm{CH}_{4}\right)$, el óxido nitroso $\left(\mathrm{N}_{2} \mathrm{H}\right)$ y los clorofluorocarburos (CFS) entre otros. Estos gases se conocen como Gases de Efecto Invernadero.

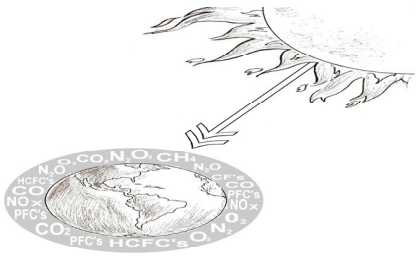

Ilustración 1.1
Los GEl absorben y reflejan las radiaciones infrarrojas provenientes del Sol. La energía solar que traspasa la atmósfera calienta la superficie terrestre. El calor generado por la superficie se refleja hacia el exterior en forma de radiación infrarroja. La radiación choca con la atmósfera, en donde una parte es absorbida por los $\mathrm{GEI}$, mientras que otra es expulsada al espacio exterior. Todo éste ciclo es conocido como Efecto Invernadero.

Una elevada concentración de GEl absorbería y reflejaría demasiada radiación solar, impidiendo que la superficie terrestre se caliente. Esto volvería a la Tierra un planeta inhabitable debido al frío extremo. Por otra parte, una concentración mínima de GEI permitiría que toda la radiación proveniente del Sol traspasara la atmósfera elevando la temperatura de la Tierra de una forma tal que sería imposible la vida en el planeta.

Por otra parte, se puede afirmar que sin la presencia de un moderado efecto invernadero la vida en la Tierra no habría sido posible.

En la ilustración 1.1 se observan los gases de efecto invernadero (GEI) y su papel en la atmósfera terrestre. En la ilustración 1.2, por otra parte, se explica de forma práctica en que consiste el efecto invernadero. Para una mejor comprensión se recomienda hacer una revisión del "ABC del Cambio Climático" publicado por el Ministerio de Medio Ambiente y Recursos Naturales (MARN)

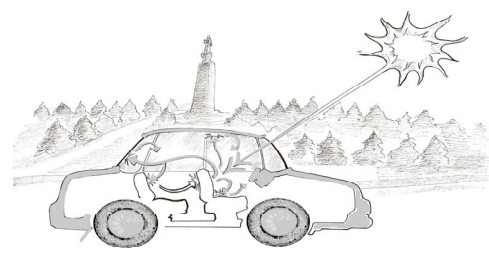

Ilustración 1.2

Las ilustraciones han sido realizadas y proporcionadas por cortesía del caricaturista salvadoreño Edgardo Trejo

\subsubsection{La agricultura y el clima}

De acuerdo a las estimaciones del Panel Intergubernamental sobre el Cambio Climático (IPCC), las regiones con niveles de desarrollo más bajos, sufrirán las mayores consecuencias debido a los altos niveles de pobreza y a que poseen una baja capacidad de adaptación.
Además, estas regiones poseen otra característica por la cual podrían verse seriamente afectadas: La producción agrícola es una de sus principales fuentes de ingresos.

A pesar de los avances tecnológicos que han tenido lugar en los últimos años, aún existe una fuerte dependencia entre la agricultura 
y el clima. Esta dependencia es mucho más evidente en países con bajo nivel de desarrollo, debido a que para algunos las técnicas de cultivo no han variado mucho en los últimos cien años.

Se sabe que las plantas dependen de cuatro factores básicos para su crecimiento y rendimientos óptimos; cantidad de agua o humedad, temperatura, luminosidad y calidad del suelo. Cualquier alteración en uno de estos cuatro factores compromete el desarrollo y los rendimientos de cualquier tipo de cultivo. Por ejemplo, la temperatura ideal para cultivar maíz blanco son $23^{\circ} \mathrm{C}$, sin embargo, manteniendo un riego adecuado se puede cultivar hasta los $28{ }^{\circ} \mathrm{C}$. Por otra parte, si la planta de maíz no recibe suficiente agua, los rendimientos se ven seriamente disminuidos, a menos que se utilicen más fertilizantes (Fontg et al. 1993).

El ejemplo de la planta de maíz permite inferir sobre los efectos que el cambio climático podría tener sobre una agricultura pobremente tecnificada. El aumento en las temperaturas y la variación en las precipitaciones pluviales podrían tener como resultado una variación en los rendimientos de los cultivos. Hay que aclarar que al mencionar los rendimientos de los cultivos se hace referencia a la cantidad de producto (medido en unidades de peso) que se obtiene al sembrar una extensión de suelo (medida en unidades de área).
Desde un punto de vista económico, tomando en cuenta los costos, un mayor rendimiento está asociado a un mayor nivel de ganancias y viceversa. Una disminución de los rendimientos de los cultivos o un incremento de los costos para mantener el mismo nivel de producción, implicará un aumento en el precio de los productos, para mantener los niveles de ganancia. Una situación que puede resultar ventajosa para los productores si se toma en cuenta que la demanda que presentan los alimentos es inelástica y dicha situación se acentúa específicamente para el maíz y frijol, por constituir el patrón alimentario en el país. Una forma más coyuntural de ver los impactos económicos del cambio climático es a través de las pérdidas directas en la producción. Suponiendo que las alteraciones en las variables climáticas no perturben directamente los rendimientos de los cultivos, la producción podría verse afectada de forma directa a través de fenómenos puntuales, como las sequías o inundaciones. En el caso que durante un ciclo agrícola se presente uno de estos fenómenos, tendrá lugar una reducción en la oferta.

Independientemente si se analiza desde un punto de vista estructural o coyuntural, el cambio climático supone a futuro una reducción en la oferta de productos agrícolas nacionales. De acuerdo a las fuerzas del mercado, la reducción en la oferta tendrá como consecuencia un aumento en los precios, 
perjudicando a los productores y consumidores, especialmente a los que se encuentran en países en vías de desarrollo como El Salvador, ya que no cuentan con seguros o contingencias para hacer frente a las pérdidas en las cosechas.

\subsection{El clima y la seguridad alimen- taria}

La agricultura cumple dos funciones esenciales para la economía: produce alimentos y materias primas para la industria, garantizando de esta forma la reproducción y el crecimiento del sistema económico.

El concepto de seguridad alimentaria permite medir la capacidad de la economía para garantizar la reproducción social. De acuerdo a la Organización de las Naciones Unidas para la Agricultura y la Alimentación (FAO) la seguridad alimentaria es un estado en el cual las personas gozan, en forma oportuna, del acceso físico, económico y social a los alimentos que necesitan en cantidad y calidad, para su adecuado consumo y utilización biológica, garantizándoles un estado de bienestar general que coadyuve al logro de su desarrollo (PESA, 2002).

La definición anterior implica las siguientes dimensiones de la seguridad alimentaria:

- Disponibilidad de alimentos. La existencia de cantidades suficientes de alimentos de calidad adecuada, suministrados a través de la producción del país o de importaciones.
- Acceso a los alimentos. Acceso de las personas a los recursos adecuados para adquirir alimentos apropiados y una alimentación nutritiva.

- Utilización. Utilización biológica de los alimentos a través de una alimentación adecuada, agua potable, sanidad y atención médica, para lograr un estado de bienestar nutricional en el que se satisfagan todas las necesidades fisiológicas.

- Estabilidad: Para tener seguridad alimentaria, una población, un hogar o una persona deben tener acceso a alimentos adecuados en todo momento. (PESA, 2002)

Anteriormente se explicó que el cambio climático podría tener como consecuencia directa la disminución en la producción agrícola. Es decir, las alteraciones en el clima podrían poner en riesgo la disponibilidad de alimentos en ciertas regiones del planeta.

La disminución de la oferta de alimentos tendrá como consecuencia un aumento de los precios. Es decir, que aunque existiera la disponibilidad adecuada de alimentos en el mercado sus precios serían elevados, impidiendo que las personas con ingresos inferiores tengan acceso a los alimentos. Por lo tanto, el cambio climático amenaza la seguridad alimentaria, tanto desde su dimensión de disponibilidad cómo desde su dimensión de acceso a los alimentos, además también afecta 
la estabilidad de la producción al provocar pérdidas por sequías y por inundaciones.

El crecimiento acelerado de las actividades económicas que se basan en el consumo de combustibles fósiles está fuertemente relacionado a la emisión de $\mathrm{GEI}$, y la mayor concentración de estos gases es la responsable de una mayor frecuencia en la aparición de manifestaciones climáticas extremas. Las principales manifestaciones de la variabilidad climática afectarán al sector agrícola, especialmente al de los países menos desarrollados. Los efectos del cambio climático se verán reflejados principalmente en la producción y como consecuencia en el precio de los alimentos. Por lo tanto, el cambio climático podría poner en peligro la seguridad alimentaria, debido a una menor disponibilidad de alimentos o una capacidad limitada para acceder a estos.

Existe cierto nivel de consenso sobre el desafío que representa el cambio climático. Por esta razón la comunidad internacional ha firmado acuerdos y conferencias con el objetivo de diseñar políticas que permitan hacerle frente al fenómeno. Por otra parte, las organizaciones responsables de estudiar el cambio climático coinciden en que uno de los principales retos que se plantea es el de garantizar la seguridad alimentaria de la población, especialmente la de los países menos desarrollados. Por lo tanto, estudiar la relación entre el cambio climático y la seguridad alimentaria en El Salvador, es una necesidad para poder afrontar los cambios que se avecinan.

\section{La disponibilidad de alimentos y el cambio climático}

De acuerdo a los objetivos planteados para realizar la presente investigación, corresponde ahora analizar la situación de la seguridad alimentaria en El Salvador. De forma más específica el presente capítulo se enfocará sobre las dimensiones de disponibilidad y acceso a los alimentos.

Para conocer si existen o no alimentos disponibles para la población demandante es necesario revisar la producción agrícola local y, en ciertos casos, las importaciones. Una vez presentados y analizados los datos se hace una comparación entre la oferta y la demanda de alimentos. Para obtener la demanda se utiliza un criterio similar a la canasta básica, es decir, la cantidad mínima de alimentos que necesita la población para satisfacer sus necesidades.

Finalmente, se hace una revisión de los principales eventos climáticos documentados en El Salvador, con el objetivo de determinar si el cambio climático influye o no en la producción de alimentos y, en consecuencia, sobre la seguridad alimentaria. 


\section{응 2.1. Las dimensiones de la segu- ridad alimentaria en El Salvador: conceptos y alcances}

Dada la pluridimensionalidad de la seguridad alimentaria, un estudio riguroso del tema sobrepasa los alcances de esta investigación. Sin embargo, desde un punto de vista económico, dos de las dimensiones citadas anteriormente revisten especial importancia: La disponibilidad de alimentos y el acceso a los alimentos. Por lo tanto, será a través de estos criterios que se realizará el análisis de la situación de la seguridad alimentaria en El Salvador. Además, debido a la cantidad casi infinita de alimentos que se encuentran, es necesario introducir otro concepto o supuesto que facilite el estudio de la seguridad alimentaria y la disponibilidad de alimentos. Se trata del concepto de patrón alimentario.

El patrón alimentario es el conjunto de alimentos que habitualmente consume la mayoría de la población, los cuales proporcionan la mayor cantidad de la energía de la dieta (Hernández, 2008). El patrón alimentario depende de la región o país que se estudie, en el caso de las culturas europeas es el trigo, el maíz para las culturas mesoamericanas y el arroz para las culturas asiáticas, por mencionar algunos. Para el caso de El Salvador, el patrón alimentario está compuesto por el maíz y el frijol, ambos productos representan más del cincuenta por ciento de la ingesta calórica en la dieta de la población salvadoreña (Hernández, 2008).

Para iniciar con la investigación se revisará en primer lugar el estado de la disponibilidad de alimentos. Es decir, la existencia de cantidades suficientes de alimentos de calidad adecuada (PESA, 2002). Pero, de acuerdo a lo anterior, cuantificar la disponibilidad de alimentos es un ejercicio complejo, debido a que se debe incluir la producción local de alimentos, sumar las importaciones y restarles las exportaciones. Además se debe restar la cantidad de alimentos que se destina a consumo animal, para reservas (semilla) y materias primas. Esta sería la forma precisa de analizar la disponibilidad de alimentos. Sin embargo, existen limitaciones inherentes a la realidad salvadoreña para realizar una investigación tan exhaustiva. Entre estas limitaciones se encuentra la poca disponibilidad de información y la calidad de la información disponible. Por lo tanto, para los casos que aplique la disponibilidad de alimentos se cuantificará mediante la producción más las importaciones y en el resto sólo mediante la producción local.

\subsection{La disponibilidad de alimentos en El Salvador}

A continuación se realiza una revisión de la capacidad del sistema para producir maíz y frijol. Posteriormente se comparan las existencias de estos productos con la demanda estimada de la producción y se compara si ha existido o no se- 
guridad alimentaria ${ }^{4}$. En el siguiente apartado se intentará determinar si ha existido alguna influencia del clima en la disponibilidad de alimentos y cuales han sido sus consecuencias, para finalmente, inferir sobre la capacidad del Cambio climático para influir a futuro sobre la seguridad en El Salvador.

\subsubsection{Oferta de granos básicos}

Antes de revisar los datos de producción, es necesario que el lector recuerde ciertos hechos que han influido en la capacidad productiva salvadoreña. En primer lugar, hay que señalar que la agricultura salvadoreña se ha caracterizado por tener un modelo de monocultivo. Este modelo se ha implementado de acuerdo a las zonas geográficas y las características propias del clima y los suelos del país. Por ejemplo en las zonas altas y montañosas se implantó el cultivo de café, mientras que en las zonas costeras, inicialmente se cultivó el algodón y posteriormente la caña de azúcar. Esta estrategia agrícola, desplazó la siembra de granos básicos (maíz y frijol) hacia pequeñas parcelas en las que los campesinos cultivaban lo necesario para su subsistencia, es decir, que en el sector de granos básicos se desarrolló un modelo de autosubsistencia.

Por otra parte, los monocultivos también influyeron en la estructura de propiedad. Con el objetivo de alcanzar rendimientos significativos era necesario contar con grandes extensiones de tierra dedicadas ex- clusivamente a los cultivos de café, algodón y caña de azúcar, por lo que la tenencia de la propiedad en manos de unos pocos terratenientes favorecía la estrategia agrícola de El Salvador. Esta estructura de propiedad generó inequidad entre la población y una baja producción de granos básicos que, al mismo tiempo, tuvo como consecuencia una elevada brecha entre las necesidades de la población y la producción real. Todo esto decantó finalmente en una inestabilidad económica y política en el país, que a finales de los años sesenta y principios de los setenta dio lugar a una reforma agraria.

La reforma agraria contemplaba desmantelar los grandes latifundios y entregarlos a pequeños productores y cooperativas. La puesta en marcha de dos de las tres etapas de la reforma permitió que a mediados de la década de 1970 se produjera un considerable aumento de la superficie que se destinaba al cultivo de maíz y frijol, y consecuentemente con este aumento en la siembra de granos básicos se produjo un aumento en la producción. Sin embargo, los errores y aciertos en la aplicación de la reforma agraria no impidieron el aumento de la inestabilidad económica, social y política del país, por lo que a inicios de la década de 1980 tuvo lugar el comienzo de la guerra civil en El Salvador.

El libre comercio generó pérdidas en el sector agrícola de los granos básicos, ya que los agricul- 
tores de subsistencia no podrían competir con el precio de los productos importados. Adicionalmente, la reducción del apoyo del Estado a la agricultura se hizo evidente con el cierre del Instituto Regulador de Abastecimiento (IRA) y la disminución de la capacidad operativa del Centro Nacional de Tecnología Agrícola (CENTA). Ambos factores influyeron para que la producción de maíz y frijol disminuyeran en comparación con los años anteriores. Para finalizar el análisis de la oferta, es innegable que la apuesta del actual gobierno por el sector agrícola está rindiendo frutos, ya que en los últimos tres años del período analizado se observa una clara tendencia al alza en la producción de maíz y frijol.

La comprensión de los factores socio-políticos y económicos que influyeron en la oferta y demanda de maíz y frijol es importante. Sin embargo, como se ha explicado anteriormente, el objetivo de la investigación está relacionado al estudio de la influencia de los factores climáticos sobre la seguridad alimentaria, por lo que a partir de este momento el análisis de las variaciones se concentrará en los aspectos climáticos.

\subsubsection{Cultivo y producción de maíz}

En el gráfico 2.1 se presentan los datos oficiales sobre área sembrada, producción y rendimientos para el cultivo de maíz. Los datos se encuentran ordenados desde 1962 hasta 2007, debido a que un período prolongado permite observar mejor las diferentes variaciones en la producción.

\section{Gráfico 1.1 Retrospectiva de producción y área sembrada de maíz. 1962-2007}

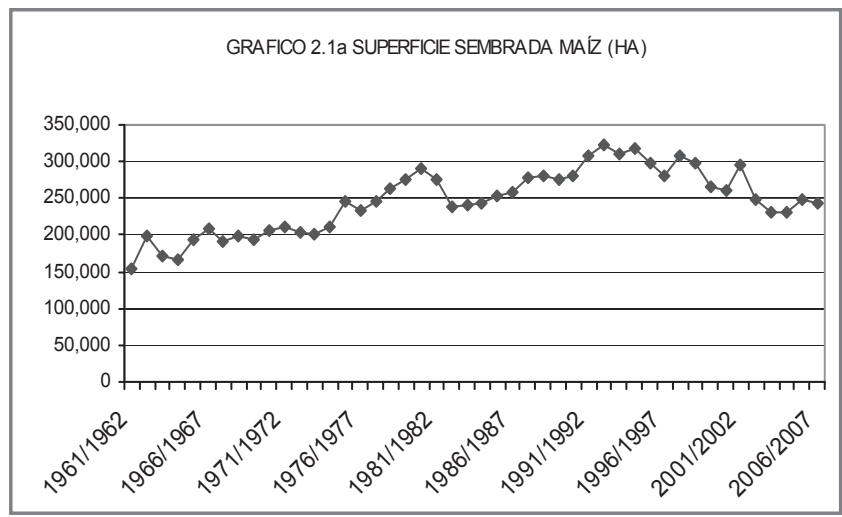



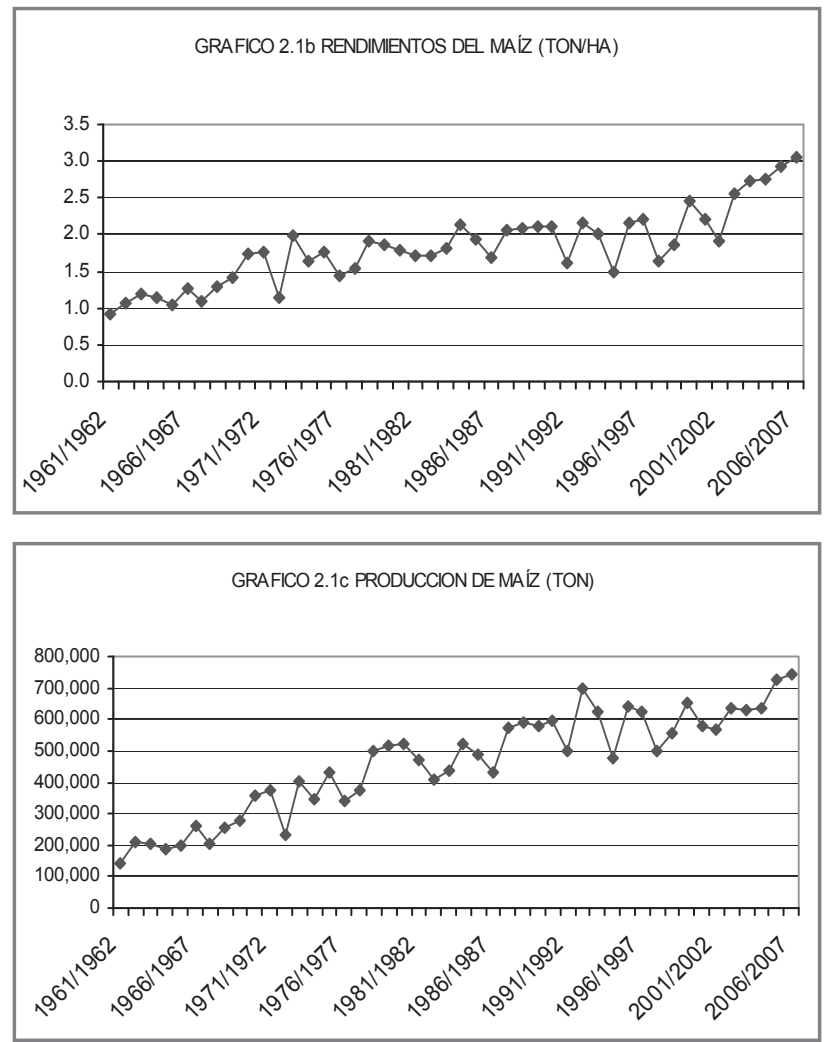

Fuente: Anuarios de Estadísticas Agropecuarias, D.G.E.A - M.A.G

En el cuadro anterior se aprecia que la producción de maíz presenta una clara tendencia al crecimiento, entre 1962 y 2007 la producción ha sufrido un incremento de más de 400 por ciento.

\subsubsection{Cultivo y producción de frijol}

Como en el caso del maíz, el gráfico 1.2 presenta una retrospec- 
Gráfico 1.2 Retrospectiva de producción y área sembrada de frijol. 1962-2007.
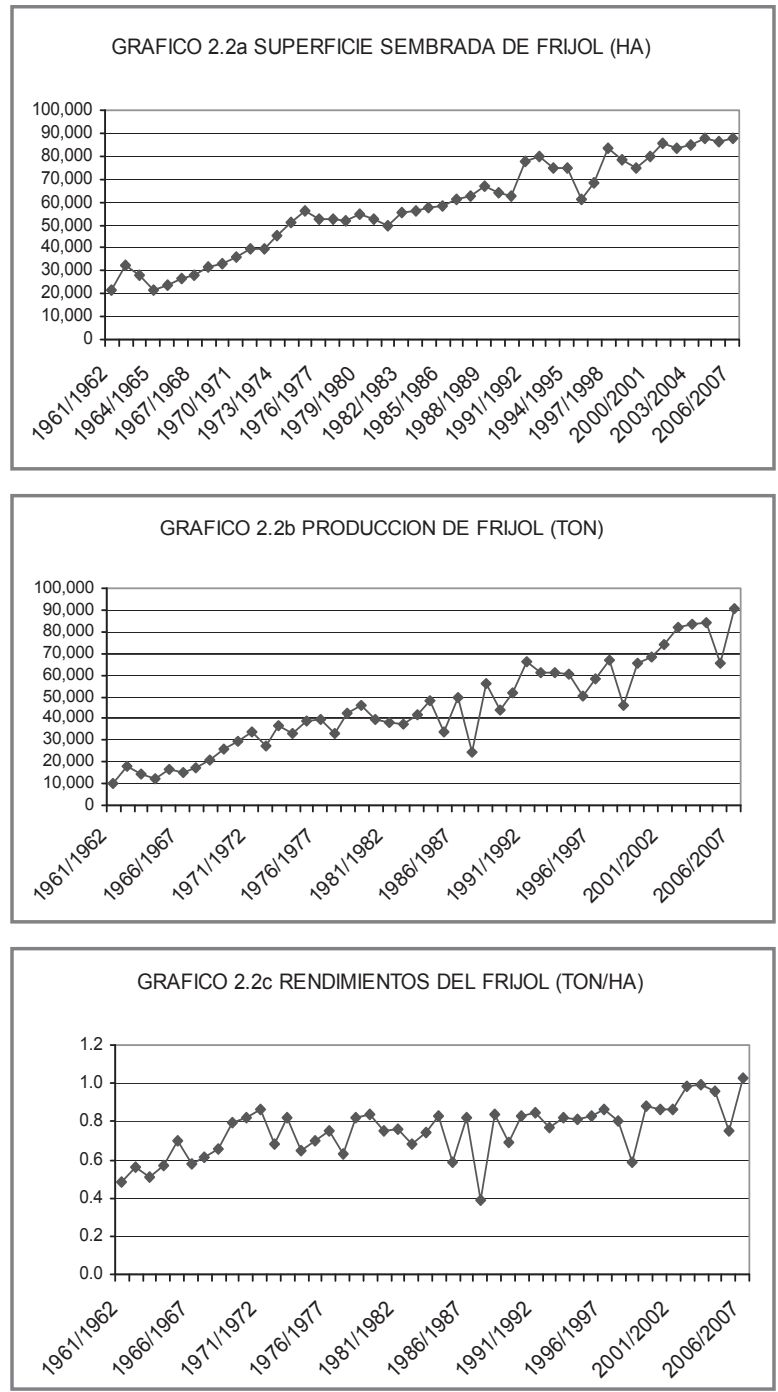

Fuente: Anuarios de Estadísticas Agropecuarias, D.G.E.A - M.A.G

En los cuarenta y seis años analizados sólo durante quince, aproximadamente, se observa un comportamiento irregular en la producción de frijol. Entre 1986 y el año 2000, la producción de frijol sufrió fuertes alteraciones. La tasa anual de crecimiento para ese período fue de 6.9 por ciento, que si bien es cierto, no afectó el 
crecimiento de la producción absoluta fue significativamente menor al resto del período. De hecho, la peor caída en la producción de frijoles tuvo lugar en el año 1988, cuando la producción fue de apenas 24,136 toneladas, más de un 50 por ciento menos que lo producido en 1987.

Cuadro 1.1 Condiciones y superficies óptimas disponibles para el cultivo de maíz y frijol en El Salvador.

\begin{tabular}{|c|c|c|c|c|}
\hline Cultivo & $\begin{array}{c}\text { Altitud } \\
(\mathbf{m s n m})\end{array}$ & $\begin{array}{c}\text { Temperatura } \\
\left({ }^{\circ} \mathbf{C}\right)\end{array}$ & $\begin{array}{c}\text { Precipitación } \\
(\mathbf{m m})\end{array}$ & $\begin{array}{c}\text { Hectáreas } \\
\text { disponibles }\end{array}$ \\
\hline Maíz & $0-600$ & $18-30$ & $600-1,200$ & 534,643 \\
\hline Frijol & $400-700$ & $15-27$ & $500-2,000$ & 471,889 \\
\hline
\end{tabular}

Fuente: Primera comunicación nacional para el cambio climático. MARN

Si se comparan las casillas de hectáreas disponibles con las de superficie sembrada de las tablas 2.1 y 2.2 se puede observar que para el año 2007 la superficie sembrada de maíz era el 53.4 por ciento de la superficie disponible. En el caso del frijol, la superficie sembrada en 2007 representó solamente el 19.2 por ciento de la superficie apta para el cultivo de frijol.

Si se toma en cuenta que los datos presentados en el cuadro 2.1 son de 1997 y que los cambios en el uso del suelo pueden haber disminuido la cantidad de tierra disponible para el cultivo de maíz y frijol, se tiene que las proporciones presentadas en el párrafo anterior podrían ser exageradas. Sin embargo, según los datos oficiales, para el año 2007 en El Salvador existían 343 mil hectáreas ociosas, de las cuales el 40 por ciento era apto para el cultivo de granos básicos (Muñoz, 2008). Por lo tanto, existen al menos 137 mil hectáreas disponibles para cultivar maíz y frijol, es decir, aún existen posibilidades de expandir la producción de forma significativa.

\subsubsection{Rendimientos}

De acuerdo a las tablas 2.1 y 2.2 los rendimientos de ambos cultivos han aumentado significativamente entre 1962 y 2007. Sin embargo, es importante aclarar que los rendimientos presentados en los cuadros son una construcción directa de las variables de superficie y producción, es decir, que no representan los rendimientos "naturales" ${ }^{5}$ de los cultivos. Por otra parte, pese a que en la elaboración de los rendimientos, el MAG, no considera las diferentes calidades de los suelos, estos rendimientos representan un parámetro importante para entender el comportamiento del cultivo de maíz y frijol.

\section{Rendimientos del maíz}

Entre 1962 y 2007 los rendimientos obtenidos del maíz han crecido en más de 179 por ciento, manteniendo una tasa de crecimiento de más de cuatro puntos porcentuales por año. Sin embargo, 
el mayor "salto de calidad" en los rendimientos se ha observado en el período 1993-2003 en el que la tasa de crecimiento anual de los rendimientos sobrepasa al resto del período en más de tres puntos porcentuales.

\section{Rendimientos del frijol}

De acuerdo a estudios realizados por el CENTA en 1998, bajo condiciones controladas el rendimiento del frijol fue de aproximadamente 1.3 Ton/Ha (CENTA, 2008). Posteriormente, en 1999 una nueva variedad de semilla cultivada en mejores condiciones produjo cerca de 1.4 Ton/Ha.

Existen diferentes factores que influyen en la variación de los rendimientos tanto en el cultivo del maíz como en el frijol, entre ellos se pueden destacar las siguientes:

- La calidad de los suelos. El $70 \%$ por ciento de la producción de maíz se realiza en laderas, por lo que no es posible esperar rendimientos más elevados.

- Un incremento en el precio de los insumos (fertilizantes y plaguicidas) impide una mayor utilización y por tanto la obtención de mayores rendimientos.

- La inestabilidad en el precio de los productos agrícolas específicamente el de los granos básicos puede desincentivar la producción de estos para consumo por una parte y por otra, orientar a los agricultores a la producción de maíz para biocombustibles.
- Las variaciones meteorológicas asociadas al cambio climático Por ejemplo, la cada vez más constante presencia del fenómeno del Pacífico o "El Niño", que incrementa la duración de las épocas secas.

\subsubsection{Demanda de granos básicos}

Hasta el momento se ha presentado el comportamiento de la producción de maíz y frijol, sin embargo, uno de los objetivos de esta investigación es analizar si el nivel de producción permite contar con la cantidad necesaria de alimentos que permita la supervivencia y reproducción de la población salvadoreña.

No existe un criterio único para determinar cual es la cantidad necesaria de alimentos que debe ingerir una persona para alcanzar la completa satisfacción de sus necesidades, esto depende de su edad, complexión física y nivel de actividad física, entre otros factores. Sin embargo, para facilitar el análisis se utilizan conceptos como el patrón alimentario y la canasta básica.

Como se ha mencionado anteriormente, el patrón alimentario es un conjunto de alimentos que consume la mayoría de la población y de los cuales obtienen la mayor cantidad de la energía que necesitan. Sin embargo, es imposible limitar la dieta de la población a uno o dos productos, por lo tanto, a partir del patrón alimentario se construye lo que se conoce como canasta básica alimentaria. 
Cuadro 1.2 Canasta básica alimentaria: Promedio nacional ${ }^{6}$ y por sectores. Vigente a diciembre de 2007

\begin{tabular}{|c|c|c|c|}
\hline \multirow{2}{*}{ ALIMENTOS } & URBANA & RURAL & $\begin{array}{c}\text { PROMEDIO } \\
\text { NACIONAL }\end{array}$ \\
\cline { 2 - 4 } & $\begin{array}{c}\text { Ingesta diaria por } \\
\text { persona (GR) }\end{array}$ & $\begin{array}{c}\text { Ingesta diaria por } \\
\text { persona (GR) }\end{array}$ & $\begin{array}{c}\text { Ingesta diaria por } \\
\text { persona (GR) }\end{array}$ \\
\hline Maíz (tortillas) & $\mathbf{2 2 3}$ & $\mathbf{4 0 2}$ & $\mathbf{3 1 2 . 5}$ \\
\hline Frijoles & $\mathbf{7 9}$ & $\mathbf{6 0}$ & $\mathbf{6 9 . 5}$ \\
\hline Arroz & 55 & 39 & 47 \\
\hline Carnes/1 & 60 & 14 & 37 \\
\hline Leche fluida & 106 & 31 & 68.5 \\
\hline Huevos & 28 & 30 & 29 \\
\hline Verduras/2 & 127 & 0 & 63.5 \\
\hline Frutas/3 & 157 & 16 & 67 \\
\hline Azúcar & 69 & 65 & 25 \\
\hline Grasas & 36 & 14 & 24.5 \\
\hline Harina (pan & 49 & 0 & 830 \\
\hline francés) & 989 & 671 & \\
\hline Total & 46 & & \\
\hline
\end{tabular}

Fuente: DIGESTYC (HERNÁNDEZ, 2008)

/1: Res, cerdo y aves.

/2: Güisquil, tomate, papa, cebolla y repollo.

13: Naranja, guineo y plátano.

/4: Manteca vegetal, margarina y aceite.

Como se puede observar en el cuadro 2.2, la canasta básica urbana contiene 11 productos, mientras que la rural solamente 9 . Por otra parte también es evidente que las cantidades varían de acuerdo a la zona en que se ubica la población, por lo que es difícil saber exactamente cuánto es la cantidad que se necesita para cubrir la necesidad de toda la población.

Retomando el hecho de que el interés de esta investigación es estudiar las necesidades de maíz y frijol, se debe adoptar una convención para determinar la demanda de estos granos. Los estudios oficiales han utilizado como requerimientos mínimos por persona 307.35 gr. de maíz y 44.77 gr. de frijoles diarios (MARN, 2000). Entonces, en concordancia con las investigaciones del MARN se utilizarán estos datos para determinar la demanda de maíz y frijol.

Una vez establecidos los requerimientos mínimos, es necesario determinar la población para la que serán aplicados. Si bien es cierto, existen proyecciones oficiales de población, con las cuales se han elaborado la mayor parte de investigaciones, resultan un poco imprecisas debido a los resultados del más reciente censo de población y vivienda realizado en el año 2007. Por lo tanto, para estudiar la demanda de maíz y frijol se ha 
optado por elaborar proyecciones propias en base a los censos de población realizados en 1961, 1971, 1992 y 2007.

Ahora que se cuenta con la población solamente se le aplican

\section{Tabla 1.1 Necesidades de maíz y frijol, de acuerdo a la población} estimada. Período 1962-2007

\begin{tabular}{|c|c|c|c|c|c|}
\hline Año & Maíz (Tons.) & Frijol (Tons.) & Año & Maíz (Tons.) & Frijol (Tons.) \\
\hline 1962 & $291,608.00$ & $42,476.90$ & 1985 & $508,244.60$ & $74,033.20$ \\
\hline 1963 & $301,876.10$ & $43,972.70$ & 1986 & $517,183.70$ & $75,335.30$ \\
\hline 1964 & $312,505.90$ & $45,521.00$ & 1987 & $526,280.00$ & $76,660.30$ \\
\hline 1965 & $323,509.90$ & $47,123.90$ & 1988 & $535,536.30$ & $78,008.70$ \\
\hline 1966 & $334,901.40$ & $48,783.30$ & 1989 & $544,955.50$ & $79,380.70$ \\
\hline 1967 & $346,694.00$ & $50,501.00$ & 1990 & $554,540.20$ & $80,776.90$ \\
\hline 1968 & $358,901.90$ & $52,279.30$ & 1991 & $564,293.60$ & $82,197.60$ \\
\hline 1969 & $371,539.60$ & $54,120.20$ & 1992 & $574,218.50$ & $83,643.30$ \\
\hline 1970 & $384,622.30$ & $56,025.80$ & 1993 & $578,649.10$ & $84,288.70$ \\
\hline 1971 & $398,165.70$ & $57,998.60$ & 1994 & $583,114.00$ & $84,939.00$ \\
\hline 1972 & $405,168.80$ & $59,018.70$ & 1995 & $587,613.20$ & $85,594.40$ \\
\hline 1973 & $412,295.00$ & $60,056.80$ & 1996 & $592,147.20$ & $86,254.90$ \\
\hline 1974 & $419,546.50$ & $61,113.00$ & 1997 & $596,716.20$ & $86,920.40$ \\
\hline 1975 & $426,925.50$ & $62,187.90$ & 1998 & $601,320.40$ & $87,591.10$ \\
\hline 1976 & $434,434.40$ & $63,281.70$ & 1999 & $605,960.10$ & $88,266.90$ \\
\hline 1977 & $442,075.30$ & $64,394.70$ & 2000 & $610,635.70$ & $88,948.00$ \\
\hline 1978 & $449,850.60$ & $65,527.30$ & 2001 & $615,347.30$ & $89,634.30$ \\
\hline 1979 & $457,762.70$ & $66,679.80$ & 2002 & $620,095.30$ & $90,325.90$ \\
\hline 1980 & $465,813.90$ & $67,852.60$ & 2003 & $624,879.90$ & $91,022.90$ \\
\hline 1981 & $474,006.70$ & $69,046.00$ & 2004 & $629,701.40$ & $91,725.20$ \\
\hline 1982 & $482,343.70$ & $70,260.40$ & 2005 & $634,560.20$ & $92,432.90$ \\
\hline 1983 & $490,827.20$ & $71,496.10$ & 2006 & $639,456.40$ & $93,146.10$ \\
\hline 1984 & $499,460.00$ & $72,753.60$ & 2007 & $644,390.40$ & $93,864.80$ \\
\hline
\end{tabular}

Fuente: Elaboración propia.

2.2.3 La diferencia entre la oferta $y$ la demanda: La brecha alimentaria

Como un resultado de la metodología empleada para obtener la población y debido a que se han tomado como constantes los los requerimientos diarios de maíz y frijol y posteriormente se obtienen los requerimientos totales para cada año en estudio. Los resultados se presentan a continuación. 
que la de frijol en más de 750 por ciento. Al comparar la producción con los requerimientos estimados se tiene que para el año 1962 existía un déficit de más de 148 mil toneladas, mientras que el déficit de frijol era de más de 32 mil toneladas. A continuación se verá si el crecimiento de la producción ha logrado superar el déficit inicial.

\subsubsection{La disponibilidad de maíz y frijol en una economía abierta}

En la tabla 2.2 se pueden apreciar las importaciones de maíz y frijol para el período 1992-2007.
Se utilizan estos años, debido a la disponibilidad de la información. Es importante aclarar que antes de 1995 no se contabilizan importaciones de frijol de forma específica. La importación de la legumbre formaba parte de una partida denominada "verduras y hortalizas". Por ello no se cuenta con datos para esos años. Otra situación importante de aclarar es que tanto en los datos de producción como en las importaciones se incluye únicamente el frijol rojo, ya que este se sitúa por encima de las preferencias de la población por aspectos puramente culturales.

Tabla 1.2 Importaciones de maíz y frijol (1992-2007)

\begin{tabular}{|c|c|c|c|c|c|}
\hline AÑO & $\begin{array}{c}\text { MAíz } \\
\text { (TONELADAS) }\end{array}$ & $\begin{array}{c}\text { FRIJOL } \\
\text { (TONELADAS) }\end{array}$ & AÑO & $\begin{array}{c}\text { MAÍZ } \\
\text { (TONELADAS) }\end{array}$ & $\begin{array}{c}\text { FRIJOL } \\
\text { (TONELADAS) }\end{array}$ \\
\hline 1992 & $63,187.00$ & 0 & 2000 & $60,471.27$ & $7,205.77$ \\
\hline 1993 & $47,674.00$ & 0 & 2001 & $92,672.73$ & $16,423.32$ \\
\hline 1994 & $145,650.00$ & 0 & 2002 & $38,005.55$ & $26,463.50$ \\
\hline 1995 & $186,867.00$ & $3,659.00$ & 2003 & $10,419.05$ & $20,764.45$ \\
\hline 1996 & $156,244.00$ & $3,191.00$ & 2004 & 0 & 765.64 \\
\hline 1997 & $78,163.55$ & 396.5 & 2005 & $87,328.05$ & 828.05 \\
\hline 1998 & $32,556.27$ & 571.05 & 2006 & 0 & 358.59 \\
\hline 1999 & $65,709.18$ & $1,761.32$ & 2007 & 0 & 226 \\
\hline
\end{tabular}

Fuente: Revistas trimestrales del Banco Central de Reserva de El Salvador

En la tabla se puede observar que no existe una tendencia marcada, existen períodos en los que las importaciones crecen mientras que en otros disminuyen de forma importante, probablemente la situación más evidente se da en el caso del maíz, en donde se observa que las importaciones de maíz blanco han Ilegado a ser nulas en 3 de los últimos cuatro años.

\subsection{La influencia de los factores climáticos en la disponibilidad de alimentos}

¿Cómo influirá el cambio climático en la agricultura de El Salvador? La respuesta a esta interrogante aún es incierta, de hecho, solamente existe un estudio realizado hasta el momento que intenta predecir el comportamiento del sector agrícola 
frente a los cambios en el sistema climático. Se trata de la primera comunicación nacional sobre el cambio climático publicada en el año 2000 por el Ministerio del Medio Ambiente y Recursos Naturales (MARN).

La investigación realizada por un panel de expertos del sector privado y del MARN establecen que los aumentos en las temperaturas y las variaciones en las precipitaciones afectarán la capacidad de los suelos para fijar nutrientes, afectando por lo tanto la capacidad de crecimiento y productividad de las plantas (MARN, 2000). Y además, establece dos probables escenarios que se podrían presentar en el país:

\section{Cuadro 1.3 Estimación de variaciones de las temperaturas y las precipitaciones en El Salvador. Años 2020 y 2100}

\begin{tabular}{|l|c|c|c|c|}
\hline \multirow{2}{*}{ VARIABLE } & \multicolumn{2}{|c|}{ ESCENARIO 1 } & \multicolumn{2}{c|}{ ESCENARIO 2 } \\
\cline { 2 - 5 } & $\mathbf{2 0 2 0}$ & $\mathbf{2 1 0 0}$ & $\mathbf{2 0 2 0}$ & $\mathbf{2 1 0 0}$ \\
\hline TEMPERATURA $\left({ }^{\circ} \mathrm{C}\right)$ & +1.1 & +3.5 & +1.1 & +3.5 \\
\hline PRECIPITACIONES $(\mathrm{mm})$ & $-11.3 \%$ & $-36.6 \%$ & $+3.5 \%$ & $+11.1 \%$ \\
\hline $\begin{array}{l}\text { VARIACIÓN ESPERADA EN LOS } \\
\text { RENDIMIENTOS DE MAIZ Y FRIJOL }\end{array}$ & \multicolumn{2}{|c|}{$-10 \% \mathrm{a}-20 \%$} & \multicolumn{2}{|c}{$0 \%$ a $10 \%$} \\
\hline
\end{tabular}

FUENTE: Primera Comunicación Nacional Sobre Cambio climático. (MARN)

Como se puede observar en el cuadro 2.3 las proyecciones se han realizado a un largo plazo, ya que en el corto plazo se pierde precisión en las estimaciones debido a la introducción de otras variables. Por otra parte, en el citado documento se establece que debido a que no se conoce con exactitud cual será el comportamiento real del clima, pueden existir dos posibles escenarios para la producción agrícola.

2.3.1 Los impactos de las sequías o canículas en la agricultura

La sequía es uno de los eventos que ocasionan más pérdidas en la agricultura. No existe una definición universal de sequía ya que depende de la ubicación geográfica de cada región, pero en términos generales se entiende por sequía a la ausen- cia de precipitaciones pluviales por un período prolongado que supera los parámetros establecidos como normales. En el país, no existen registros de sequías muy prolongadas como en algunos países africanos. Sin embargo, existe un importante nivel de incidencia de este fenómeno en la agricultura.

La mayor parte de pérdidas ocasionadas por sequías han tenido lugar en el cultivo de maíz. La mayor disminución tuvo lugar en la cosecha 1972/73, cuando la producción cayó en más de $37 \%$. Ese año, la brecha alimentaria pasó de 32 mil toneladas (aproximadamente) hasta llegar a más $178 \mathrm{mil}$ toneladas, es decir, un incremento de $449 \%$ en la diferencia entre lo que la población necesita y lo que se produce. 
Tras la sequía de 1972, no hubo otra que afectase más la producción de maíz. Y si bien es cierto la capacidad de la economía para resistir una sequía ha mejorado, hay que recordar que cada una de las sequías ha tenido un comportamiento diferente y para lo alcances de esta investigación es imposible afirmar que una es menos severa que la anterior. Por ejemplo, la sequía que tuvo lugar en 2004 arroja pérdidas de un $1 \%$ aproximadamente, sin embargo, el impacto en la población fue evidente, algunos campesinos de la zona oriental afirmaron: "No hay maíz ni para tortillas, ni (dinero) para comprar arroz o frijoles" (Villarroel y Ventura, 2008).

\subsubsection{Los impactos de las inunda- ciones en las cosechas}

Otro fenómeno que tiene un impacto importante en las cosechas de granos básicos son las inundaciones causadas por lluvias torrenciales. Los efectos de las inundaciones suelen ser menores a los producidos por las sequías, sin embargo, existen evidencias tangibles de las pérdidas ocasionadas por estos fenómenos. Por ejemplo, de acuerdo a un informe de la CEPAL-PNUD, en 2005 las inundaciones ocasionadas por la depresión tropical Stan provocaron la pérdida de más de 60,000 hectáreas de tierra cultivada, especialmente de maíz y frijol.

La mayor parte de las inundaciones que han tenido lugar en el país se han presentado en el departamento de San Salvador. Después de San Salvador, las inundaciones se reparten de forma cuasi uniforme entre los departamentos que limitan con la zona costera como Usulután $(7.92 \%)$ La Paz $(6.37 \%)$ y San Vicente $(6.37 \%)$. Además, algunos departamentos con caudales pluviales importantes como San Miguel y La Unión han sufrido el 9.07y 8.88 por ciento de las inundaciones, respectivamente. En el mapa 2.1 se pueden apreciar las zonas de El Salvador que en el presente y probablemente en el futuro se encuentren en una situación de mayor vulnerabilidad ante las inundaciones. 


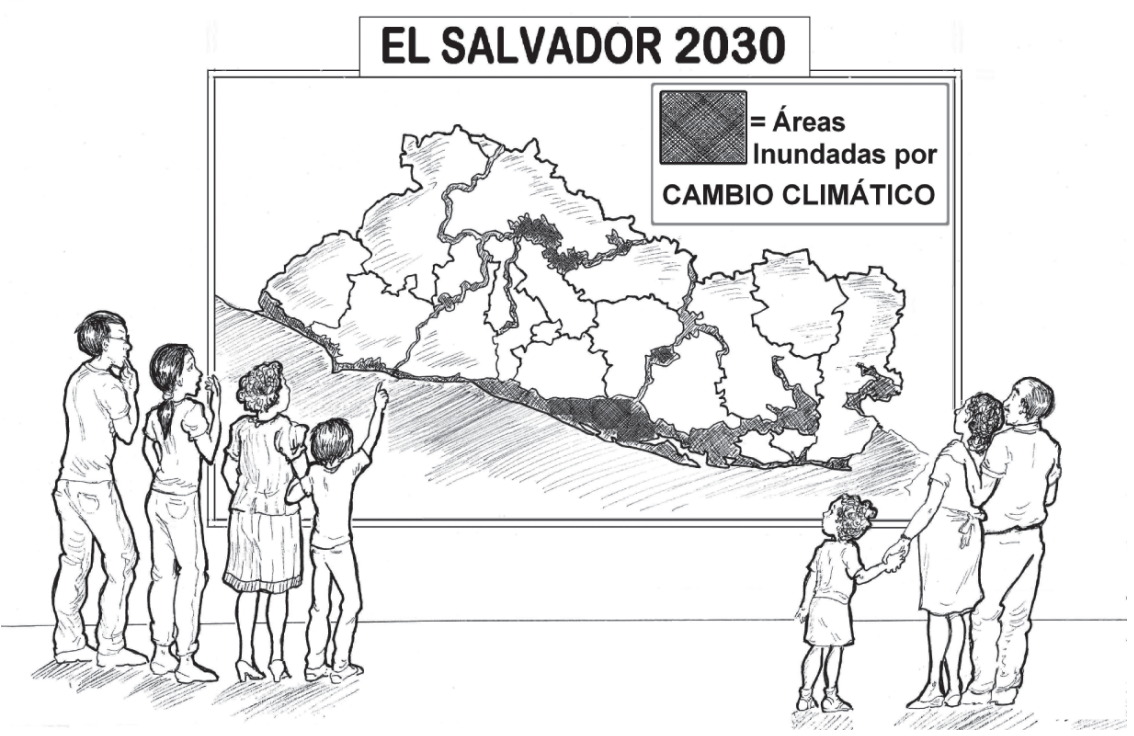

Fuente: Ilustración del caricaturista salvadoreño Edgardo Trejo, con base a escenarios establecidos por el Ministerio de Medio Ambiente y Recursos Naturales.

La información proporcionada por el mapa 1.1 también coincide con los registros históricos de zonas vulnerables a las sequías. Las áreas obscuras indican las zonas de mayor riesgo. Las zonas costeras del departamento de La Paz y San Vicente son unas de las más vulnerables debido a la cercanía a caudales hídricos importantes como el río Lempa y el Jiboa.

Una vez identificadas las zonas vulnerables, es importante tratar de comprender el grado de incidencia que las inundaciones tienen sobre los cultivos. En el mapa 2.2 se pre- senta la distribución geográfica de las áreas cultivadas de maíz en El Salvador. Si bien es cierto la información presentada en el mapa es para la cosecha 2002/03, esta distribución resulta ser un buen punto de referencia para comprender en qué grado se puede ver afecto el cultivo de maíz debido a las inundaciones. De acuerdo al mapa 2.2, las zonas sombreadas más obscuras son las zonas productoras de maíz. A simple vista, se aprecia que los cinco principales productores de maíz son Usulután, Santa Ana, Ahuachapán, La Libertad y San Miguel. 


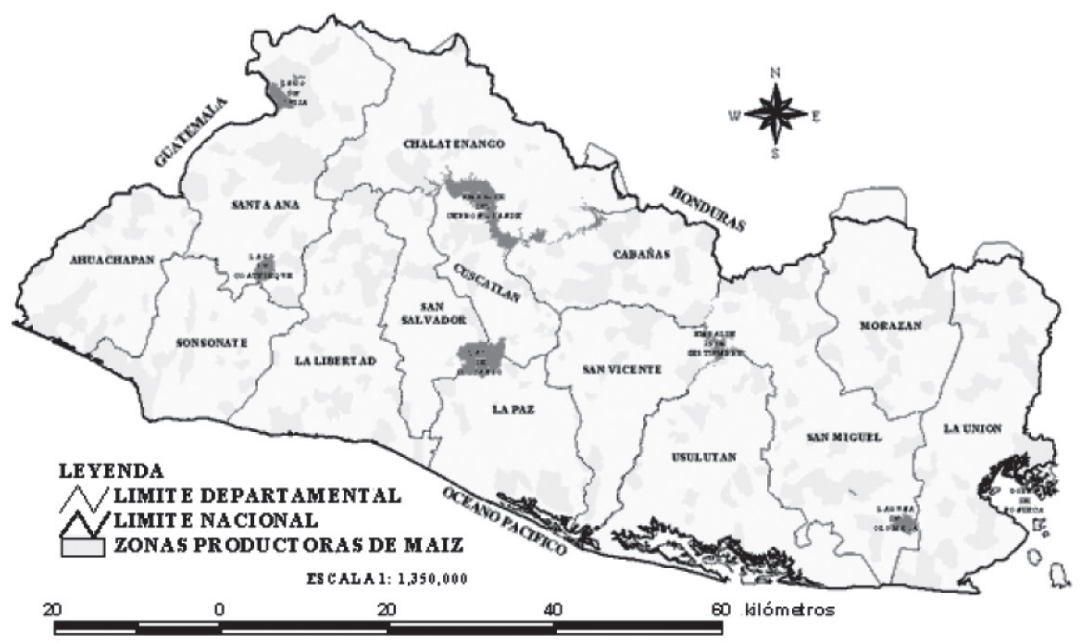

Fuente: http://www.camagro.com/mag/Anuario_Estadisticas/2002-2003/Estadisticas_Agropecuarias/Anexos/Maiz.asp 26/08/2008

\subsection{Conclusiones}

La imposibilidad del sector agrícola para garantizar la disponibilidad de alimentos debe tener sus cimientos en la estructura productiva misma, ya que a lo largo de todo el período analizado no existe un período en el que se pueda afirmar que la seguridad alimentaria está garantizada.

Si bien es cierto, la inseguridad alimentaria en El Salvador resulta ser un fenómeno asociado a la estructura económica y productiva de la economía, las variaciones climáticas han representado un obstáculo para alcanzar mayores niveles de producción. El Cambio climático es entonces una variable que debe ser tomada en cuenta en el diseño de políticas encaminadas a garantizar la disponibilidad de alimentos. La escasa disponibilidad de alimentos en el pasado ha dificultado el acceso a los mismos. En la siguiente sección se dará un vistazo a esta otra dimensión de la seguridad alimentaria.

\section{Segunda dimensión de la seguridad alimentaria: \\ El acceso a los alimentos}

La problemática de la seguridad alimentaria no sólo abarca la producción de alimentos, también implica que, la población pueda adquirir los alimentos producidos. En El Salvador, como en el resto del mundo, el acceso a los alimentos viene dado por el nivel de precios, los ingresos individuales y la pro- 
ducción. En muchos casos se debe incluir también a aquellas actividades destinadas al autoconsumo.

Si bien es cierto se ha demostrado que existe cierta capacidad de aprovisionamiento de maíz y frijol, aún bajo la influencia del cambio climático, esta situación por sí sola no garantiza la seguridad alimentaria del país.

\subsection{Mercado de frijol y maíz}

\subsubsection{Mercado de frijol}

Para facilitar el estudio de la producción de frijol en el país, el Ministerio de Agricultura y Ganadería (MAG) ha dividido en territorio salvadoreño en cuatro regiones productoras. Su composición y su participación en la producción total se presentan a continuación (IICA, 2008).

\begin{tabular}{|c|l|c|}
\hline REGIÓN & \multicolumn{1}{|c|}{$\begin{array}{c}\text { DEPARTAMENTOS QUE } \\
\text { CONFORMAN CADA REGIÓN }\end{array}$} & $\begin{array}{c}\text { PARTICIPACIÓN EN } \\
\text { LA PRODUCCIÓN } \\
\text { NACIONAL DE FRIJOL }\end{array}$ \\
\hline I & Ahuachapán, Santa Ana y Sonsonate & $27 \%$ \\
\hline II & $\begin{array}{l}\text { Chalatenango, La Libertad, San } \\
\text { Salvador y Cuscatlán }\end{array}$ & $41 \%$ \\
\hline III & La Paz, Cabañas y San Vicente & $22 \%$ \\
\hline IV & $\begin{array}{l}\text { Usulután, San Miguel, Morazán y La } \\
\text { Unión }\end{array}$ \\
\hline
\end{tabular}

El cultivo de frijol puede realizarse en tres épocas de siembra que son: Primera, postrera y apante ${ }^{7}$. Sin embargo, debido a la ubicación geográfica de El Salvador, la siembra de frijol se lleva a cabo principalmente en las épocas primera y postrera.

Las técnicas utilizadas en el cultivo del frijol generalmente son de tipo artesanal y poco desarrolladas, por lo que los costos de producción varían constantemente, sin embargo, de acuerdo a la Dirección General de Estadísticas Agropecua- rias (DGEA) del MAG, el costo de producción por quintal producido en época de invierno para el año 2006 fue de \$27.50 mientras que el quintal de frijol producido en época de verano se fijó en \$26.85

Si se considera que, en el 2006, el precio promedio de un quintal de frijol para los mayoristas fue de $\$ 39.07$, se podría pensar que el agricultor obtuvo una ganancia de aproximadamente $\$ 11.57$. El precio pagado por kilogramo de frijol en las diferentes etapas de comercio se muestra en la tabla 3.1. 
Tabla 2.1. Cadena de precios de la producción y comercialización del frijol en El Salvador.

\begin{tabular}{|c|c|c|c|c|c|}
\hline & $\begin{array}{c}\text { Costo de } \\
\text { Producción }\end{array}$ & Productor & Transportista & Mayorista & $\begin{array}{c}\text { Consumidor } \\
\text { Final }\end{array}$ \\
\hline 2002 & & 0.63 & 0.65 & 0.69 & 0.84 \\
\hline 2003 & & 0.49 & 0.49 & 0.52 & 0.75 \\
\hline 2004 & & 0.62 & 0.73 & 0.77 & 1.01 \\
\hline 2005 & $0.65^{*}$ & 0.83 & 0.85 & 0.89 & 1.17 \\
\hline 2006 & & 0.72 & 0.74 & 0.79 & 1.12 \\
\hline 2007 & & 0.91 & 1.00 & 1.04 & 1.36 \\
\hline
\end{tabular}

* El costo de producción no incluye el transporte del producto desde la parcela hasta el punto de venta o hasta el punto de acopio, los cuales se estiman en 1 a 2 dólares/qq; es decir, $\$ 0.033 / \mathrm{kg}$ adicionales al costo de producción.

Fuente: Guía para la exportación de frijol rojo a Guatemala

El mercado mayorista de frijol se concentra en pocas empresas, esto es, presenta una estructura oligopólica, que tiene la capacidad de influir en los precios de compra al productor y de venta al consumidor. La tabla 3.1 refleja que el margen de ganancia en cada eslabón dentro del mercado es bastante limitado por no decir nulo, dentro de esta cadena son los distribuidores los que obtienen mayor ganancia por ser los que se apropian de la deferencia en el precio dentro del mercado mayorista y el precio al consumidor final.

La demanda y la forma de consumo inciden de manera importante en los volúmenes de siembra y comercialización del frijol en El Salvador. El consumo del grano, no implica serios procesos de transformación, debido a que por costumbre o tradición generalmente se consume bajo simples procesos de cocción. Sin embargo existe el desarrollo incipiente de industrias de frijoles congelados, enlatados y de empaque del grano.

\subsubsection{Mercado de maíz}

Al igual que cultivo del frijol, el volumen de producción del maíz blanco a nivel de la región centroamericana se le atribuye a pequeños productores, en sistemas geográficos aislados y sin una organización establecida, lo que imposibilita que el cultivo del maíz les reporte los ingresos suficientes para el desarrollo formal del cultivo (IICA, 2008).

En el país la cosecha de maíz se lleva cabo en dos épocas del año la primera del 15 de mayo al 15 de junio y la segunda del 15 de junio al 31 de agosto. $Y$ al igual que en el caso del frijol, el Ministerio de Agricultura y Ganadería, MAG, ha divido el territorio en cuatro 


\begin{tabular}{|c|c|c|}
\hline REGIÓN & $\begin{array}{l}\text { DEPARTAMENTOS QUE CONFORMAN } \\
\text { CADA REGIÓN }\end{array}$ & $\begin{array}{c}\text { PARTICIPACION EN LA } \\
\text { PRODUCCION NACIONAL } \\
\text { DE MAÍZ }\end{array}$ \\
\hline I & Ahuachapán, Santa Ana y Sonsonate & $30 \%$ \\
\hline II & $\begin{array}{c}\text { Chalatenango, La Libertad, San Salvador } \\
\text { y Cuscatlán }\end{array}$ & $33 \%$ \\
\hline III & La Paz, Cabañas y San Vicente & $17 \%$ \\
\hline IV & $\begin{array}{c}\text { Usulután, San Miguel, Morazán y La } \\
\text { Unión }\end{array}$ & $20 \%$ \\
\hline
\end{tabular}

Es importante destacar que El Salvador ocupa el primer lugar en Centroamérica, en cuanto a rendimientos del cultivo de maíz, registrando 2.93 Ton/Ha. Este rendimiento es un valor promedio de los rendimientos obtenidos en el volumen de maíz producido a través de los tres procesos: Semitecnificados, tecnificado y semilla mejorada ${ }^{8}$, los cuales, influyen tanto en los rendimientos como en los costos. De acuerdo a datos de la DGEA-MAG, correspondientes a 2006, el costo por quintal de maíz tecnificado fue de $\$ 8.67$; mientras que el quintal de maíz semitecnificado fue de $\$ 10.15$. Finalmente, el precio del quintal de maíz tradicional se fijó en $\$ 12.40$

El nivel de rendimientos y de costos, le permiten a El Salvador ser el principal exportador de maíz a nivel de Centroamérica. Sin embargo, al igual que en el caso del frijol, la cadena de distribución del maíz está en manos de pocas empresas que conocen el mercado nacional y que tienen la capacidad de influir en los precios de mercado.

Los principales centros de distribución del maíz y frijol dependiendo de la finalidad de la compra ya sea para consumo o redistribución son básicamente 3: Mercados populares, supermercados y a través de pequeños productores. En los supermercados se estima que mensualmente se comercializan alrededor de 53,000 quintales de frijol, los cuales son comprados a empresas como Dilosa, Omoa y Arrocera San Francisco. Es importante destacar que la mayoría de la población tiene acceso a los alimentos en centros de comercio informal como los mercados populares o por pequeños productores (IICA, 2008).

La versatilidad del maíz permite que pueda utilizarse para consumo humano o consumo animal. Entre los usos que se pueden hacer de este grano están la fabricación de harinas, tortillas, tamales $\mathrm{u}$ otros 
derivados del maíz, estas actividades de transformación pertenecen a procesos generalmente artesanales. En El Salvador, el consumo de derivados del maíz como bocadillos y harina empacada, muestra una tendencia creciente. Sin embargo, gran parte de la población, incluyendo a una buena parte del área urbana todavía depende de elaboración artesanal de tortillas.

\subsubsection{El precio de los alimentos: maíz y frijol}

Un importante indicador de la capacidad de la economía para garantizar la seguridad alimentaria de la población es el precio de los alimentos. A ese respecto se tienen que desde 1992 hasta el año 2007 el precio al por mayor de maíz y del frijol ha aumentado considerablemente.

Anteriormente, se estableció que ha existido un incremento en la producción de maíz y frijol, sin embargo, debido a las prácticas tradicionales de producción y a las malas condiciones topográficas en las que se desarrolla el cultivo, no se observa una clara influencia en el precio del maíz y frijol para los consumidores. De hecho, como se puede observar en la tabla 3.1 existe una importante diferencia entre el precio que se le paga al productor y el que paga el consumidor final, por lo tanto uno de los principales factores que influye en el precio de los granos básicos es el margen de ganancias de los intermediarios.
Además, el aumento constante del volumen de producción parece no ser sostenible en el largo plazo y difícilmente podría contribuir a posicionar a El Salvador como exportador neto de maíz y frijol. Por otra parte, el nivel de precios y la capacidad de la economía salvadoreña para generar ingresos que los compensen, mantiene en constante riesgo la seguridad alimentaria de muchas familias, especialmente las más pobres.

\subsection{Ingresos y empleo}

Como resultado del crecimiento económico experimentado luego de la firma de los Acuerdos de Paz, el Ingreso Nacional Disponible per cápita para 1992 fue de $\$ 1,100.00$, lo cual ubica a El Salvador dentro de los 54 países con renta media baja ${ }^{9}$. Sin embargo, a pesar de esta clasificación, los niveles de pobreza extrema no se han visto reducidos. Pese a los esfuerzos, todo parece indicar que las políticas gubernamentales orientadas a erradicar la pobreza han generado una mayor desigualdad y un crecimiento carente de equidad, radicado especialmente en el área rural.

Los índices de distribución de ingreso permiten inferir que el fruto del crecimiento económico logrado a partir de los Programas de Ajuste Estructural (PAE), no ha llegado a todos los sectores de la sociedad. Basta con referirse a los ingresos per cápita mensuales para el área rural y urbana, que para el 
2006 fueron de $\$ 64.86$ y $\$ 138.66$ respectivamente (DIGESTYC, 2006). Sin el ánimo de profundizar en los determinantes de la desigualdad en los niveles de ingreso por causas geográficas, se sabe que existe una contradicción implícita del modelo de crecimiento de El Salvador, que impide la satisfacción completa de necesidades tan básicas como la alimentación.

El nivel de ingresos que se registra en zonas rurales y en zonas urbanas, al compararse con el precio promedio anual de la canasta básica alimentaria rural y urbana al 2006, que fue de $\$ 97.10$ y $\$ 144.00$ respectivamente, refleja una insuficiencia del ingreso para darle cobertura a la canasta básica alimenticia. La situación parece agravarse si se toma en cuenta que la canasta básica alimentaria constituye sólo el 36 por ciento de la canasta de mercado y si los ingresos no permiten siquiera cubrir este rubro, la situación para el salvadoreño o salvadoreña promedio, se traduce en que no pueden asegurar una buena alimentación al mes.

De acuerdo a la Organización Internacional del Trabajo (OIT), el salario mínimo es el ingreso que debería garantizar vida digna a los trabajadores de un país, región o sector de actividad económica y también el nivel de salario debajo del cual sería socialmente inaceptable contratar mano de obra (OIT, 1970). A partir de esta definición se puede afirma que el salario mínimo en El Salvador, no es una condición suficiente que garantice la reproducción material de la mayoría de la población.

Por otra parte, el sector agrícola en la actualidad alberga al 18.3 por ciento de la fuerza de trabajo ocupada, registra la menor remuneración salarial (PNUD, 2008). Sin embargo, al comparar la evolución del salario mínimo nominal agropecuario con el costo de la canasta básica alimentaria rural, se evidencia de forma notable una insuficiencia en la cobertura de dicha canasta. En el año 2007, el diferencial de insuficiencia del salario mínimo con relación a la canasta básica alimentaria fue de $\$ 30.00$, lo que coloca a la población que reside en zonas rurales en una situación de vulnerabilidad, debido a la imposibilidad de contar con un ingreso que al menos les garantice el acceso a los alimentos ${ }^{10}$.

La remuneración salarial para los sectores servicios, comercio y maquila es superior a la que se recibe por trabajos en el sector agropecuario, sin embargo el margen de cobertura con relación a la canasta básica es todavía muy estrecho. A finales del año, 2007 el monto del salario mínimo nominal para el sector servicios y comercio, sobrepasaba el costo de la canasta básica urbana en alrededor de $\$ 24.60$, esta cifra no era alentadora si se tomaba en cuenta que para el sostenimiento básico de una familia, dicho remanente debía distribuirse entre otros rubros igualmente importantes, como gastos de transporte, salud, educación, 
etc. El panorama no parece mejorar para el caso de la remuneración en el sector maquila, para el año 2007 el remanente del salario que reportó luego de descontarle el valor de la canasta básica fue de \$3.60. La tabla 3.2 muestra la comparación entre el salario mínimo nominal por sector el costo de la canasta básica alimentaria.

\section{Tabla 2.2. Valor de los salarios mínimos y el precio de la canasta básica}

\begin{tabular}{|c|c|c|c|c|c|}
\hline & $\begin{array}{c}\text { Sector } \\
\text { comercio y } \\
\text { servicios }\end{array}$ & $\begin{array}{l}\text { Sector } \\
\text { maquila }\end{array}$ & $\begin{array}{c}\text { Sector } \\
\text { agropecuario }\end{array}$ & $\begin{array}{c}\text { Canasta } \\
\text { básica } \\
\text { alimentaria } \\
\text { (Rural) }\end{array}$ & $\begin{array}{c}\text { Canasta } \\
\text { básica } \\
\text { alimentaria } \\
\text { (Urbana) }\end{array}$ \\
\hline 1992 & $\$ 92.89$ & $\$ 92.89$ & $\$ 44.72$ & nd & nd \\
\hline 1993 & $\$ 106.85$ & $\$ 106.85$ & $\$ 55.02$ & $\$ 73.81$ & $\$ 105.45$ \\
\hline 1994 & $\$ 120.41$ & $\$ 120.41$ & $\$ 61.93$ & $\$ 74.55$ & $\$ 98.84$ \\
\hline 1995 & $\$ 125.57$ & $\$ 125.57$ & $\$ 68.12$ & $\$ 76.93$ & $\$ 100.77$ \\
\hline 1996 & $\$ 125.57$ & $\$ 125.57$ & $\$ 68.12$ & $\$ 88.35$ & $\$ 113.26$ \\
\hline 1997 & $\$ 125.57$ & $\$ 125.57$ & $\$ 68.12$ & $\$ 84.60$ & $\$ 110.79$ \\
\hline 1998 & $\$ 144.00$ & $\$ 144.00$ & $\$ 74.10$ & $\$ 90.10$ & $\$ 123.51$ \\
\hline 1999 & $\$ 144.00$ & $\$ 144.00$ & $\$ 74.10$ & $\$ 85.22$ & $\$ 111.31$ \\
\hline 2000 & $\$ 144.00$ & $\$ 144.00$ & $\$ 74.10$ & $\$ 85.63$ & $\$ 114.28$ \\
\hline 2001 & $\$ 144.00$ & $\$ 144.00$ & $\$ 74.10$ & $\$ 88.79$ & $\$ 119.45$ \\
\hline 2002 & $\$ 144.00$ & $\$ 144.00$ & $\$ 74.10$ & $\$ 93.30$ & $\$ 128.70$ \\
\hline 2003 & $\$ 158.40$ & $\$ 151.20$ & $\$ 74.10$ & $\$ 91.90$ & $\$ 128.80$ \\
\hline 2004 & $\$ 158.40$ & $\$ 151.20$ & $\$ 74.10$ & $\$ 98.90$ & $\$ 132.40$ \\
\hline 2005 & $\$ 158.40$ & $\$ 151.20$ & $\$ 74.10$ & $\$ 101.50$ & $\$ 138.00$ \\
\hline 2006 & $\$ 174.24$ & $\$ 157.25$ & $\$ 81.51$ & $\$ 97.10$ & $\$ 144.00$ \\
\hline 2007 & $\$ 183.00$ & $\$ 162.00$ & $\$ 85.80$ & $\$ 115.80$ & $\$ 158.40$ \\
\hline
\end{tabular}

Fuente: Elaboración propia, con base a datos de la Dirección General de Estadísticas y Censos

Puede afirmarse que el acceso a la cantidad de alimentos necesarios y suficientes que satisfagan los requerimientos energéticos de una buena parte de la población no es seguro, y está afectado principalmente por la falta de adecuados ingresos (en este caso los salarios). La situación del empleo y los salarios en El Salvador es una realidad Ilena de contrastes y ha determinado la situación de pobreza heterogénea que caracteriza al país.

\subsubsection{Pobreza extrema y pobreza relativa}

Para el año 1992, un 34 por ciento de los hogares rurales y 21.9 por ciento de hogares en el área urbana se encontraba en situación de pobreza extrema. Hacia el año 2006 parece que las políticas impulsadas por el gobierno han tenido efecto sobre el porcentaje de hogares en extrema pobreza, al haber reducido dicho porcentaje a 12.2 por 
ciento en el área rural y al 8.0 por ciento en el área urbana, aunque el mayor porcentaje se mantiene siempre para el área rural.

Históricamente, la pobreza en El Salvador ha sido una característica de la zona rural, por ser esta la que registra el menor nivel de ingresos y porque las condiciones bajo las que se produce no son capaces de generar el excedente necesario. En primer lugar porque muchas veces se cultiva para autoconsumo y en segundo lugar porque no tienen la legalidad de la tierra para poderla explotar.

Geográficamente, los departamentos que concentran a la mayoría de hogares en condición de extrema pobreza son: Ahuachapán, con el 15.73 por ciento; Chalatenango, 14.01 por ciento; Cuscatlán, 17.45 por ciento; Cabañas, 18.7 por ciento; San Vicente, 14.49 por ciento y Morazán, 19.43 por ciento (DIGESTYC, 2006).

Si se suma el total de hogares urbanos y rurales en pobreza extrema del país, se tiene que alrededor del 20 por ciento de la población nacional no cuenta con ingresos suficientes que garanticen el acceso oportuno y en cantidades adecuadas de alimentos. Ello coloca a este porcentaje de la población en una posición de vulnerabilidad frente a enfermedades y la desnutrición, que pueden diezmar sus capacidades físicas y productivas. Si bien es cierto que no se ha demostrado de forma precisa la influencia del clima en la producción de alimentos, es evidente que el cambio climático deberá jugar un papel importante en la agricultura para los próximos años, y si este fenómeno se acentúa, la población estará doblemente vulnerable al acceso eficiente y oportuno de los alimentos.

\subsection{Visión estructural del aprovisio- namiento y acceso a los alimentos en El Salvador}

La dinámica del modelo capitalista, conforme contribuye al logro de "estadios económicos superiores", presupone cambios en la estructura productiva de las economías y el caso particular de El Salvador, esto no ha sido una excepción; el sector agrícola que a inicios del siglo XX constituía el soporte principal de la economía salvadoreña, a finales de la década de los noventa solamente contribuía un 11 por cierto al volumen de producción total, cediendo el 89 por ciento de contribución a la producción a los sectores industria, comercio y servicios.

\subsubsection{El aprovisionamiento de ali- mentos}

El sector agrícola ha cargado con el abandono económico del Estado los últimos 25 años, lo que se ha traducido en una pobre participación dentro del volumen de producción agrícola total. Sin embargo, esta situación no recae únicamente en la falta de incentivos económicos por parte del Estado a este sector, la situación que atraviesa el sector agrícola viene dada 
también por condiciones culturales y sociales, no corregidas a través de las políticas económicas ejecutadas por el Estado.

El volumen de producción agrícola y específicamente el cultivo de frijol y maíz no han registrado tendencias estables al alza y en muchos de los años analizados, la producción de estos granos no ha superado la demanda de la población, orillando a que el consumo de estos granos sea suplido a través de las importaciones. Por otra parte, las extensiones de tierra destinadas al cultivo de maíz y frijol están muy por debajo de la frontera de producción y las tierras que han estado o están cultivadas, son consideradas como terrenos no aptos y/o vulnerables a la desertificación.

La capacidad de la economía para garantizar el aprovisionamiento de maíz y frijol, ha estado limitada por condiciones históricas de falta de recursos económicos y tecnológicos, que - sumados a las condiciones físicas del terreno en el cual se cultivan - imposibilitan se alcancen los rendimientos óptimos por hectárea, reduciendo así el margen de cobertura de la demanda, $y$ traduciéndose en una situación de vulnerabilidad del país para satisfacer con sus propios recursos la seguridad alimentaria.

El clima como variable exógena al modelo, pero con gran incidencia sobre las condiciones propicias para el cultivo juega un papel importante con relación directa al volumen de producción, mientras las condiciones climáticas sean las adecuadas a la época de siembra y se mantengan a lo largo del período de crecimiento hay una mayor probabilidad que el volumen de producción aumente, caso contrario ocurriría si en el territorio agrícola, las variabilidades climáticas aumentaran a extremos que imposibiliten la germinación, crecimiento o desarrollo de la semilla. El cambio climático a partir de alterar las condiciones climáticas naturales acentuaría el grado de vulnerabilidad del país para garantizar el volumen adecuado de aprovisionamiento de frijol y maíz.

\subsubsection{El acceso a los alimentos}

La insuficiencia de los salarios para garantizar el acceso adecuado a los alimentos ha sido una condición histórica y tiene sus raíces en la inequitativa distribución del ingreso en el país.

A pesar que, de acuerdo a las cifras oficiales, El Salvador se ha convertido en un país con renta media alta, todavía hay un porcentaje considerable de hogares que no tienen el nivel de ingresos mínimo que les garantice el acceso oportuno y suficiente de alimentos. Los datos correspondientes a los salarios mínimos nominales evidencian la insuficiencia de estos para subsanar los requerimientos mínimos de alimentación y esta condición se acentúa en aquellas zonas propicias para actividades agrícolas que están alejadas de los centros de desarrollo económico. Las zonas rurales se 
caracterizan por su lejanía de los "centros urbanos de desarrollo", por contar con una población con bajo nivel de educación, por la preponderancia del trabajo reproductivo sobre el productivo, etc.

Por otra parte, un gran porcentaje del área rural del país está destinada a actividades agrícolas y muchas de las familias que se dedican a estas actividades no reciben una remuneración o incentivos por parte del Estado que garanticen el acceso a los alimentos. Además, hay que recordar que aún cuando el sector agrícola alberga a más del 18 por ciento de la población, los salarios mínimos más bajos del país recaen en este sector.

Como se ha explicado, buena parte de la población de las zonas rurales se dedica a las actividades agrícolas y está expuesta a un mercado viciado, desorganizado, con bajos niveles tecnológicos y productivos y a su vez con bajos niveles de salarios, por lo tanto, son el segmento de población más vulnerable a las alteraciones ajenas al mercado que puedan diezmar lo poco que producen. Por todo esto, el cambio climático, a través de las alteraciones en el sistema climático, puede reducir aún más las oportunidades de ingreso de estas familias y limitar el acceso de alimentos en otras. Hay que recordar que por ser la población que se desempeña en áreas agrícolas la más vulnerable por no contar con un nivel de ingresos establecido y el poco que perciben depende de la producción de los cultivos que realicen, cualquier factor que disminuya el volumen de producción, reducirá sus oportunidades de ingresos.

\subsection{Principales consecuencias eco- nómicas y sociales de la influencia del cambio climático sobre la segu- ridad alimentaria}

El cambio climático puede aumentar más la vulnerabilidad de las familias pobres. La aparición de sequías o inundaciones dificultará el acceso a los alimentos, por parte de este creciente sector de la población. Primero porque reduciría la frontera de posibilidades de producción agrícola y segundo porque actuaría a través del mecanismo de mercado, iniciando con la contracción de la oferta de alimentos para luego aumentar el precio de los mismos. Además, el carácter esencial y no sustitutivo de los alimentos, les otorga a estos bienes un tipo de demanda inelástica, por lo tanto, las familias más pobres tendrán que renunciar a otros bienes para poder tener acceso a los alimentos. Algunos mecanismos por medio de los cuales el cambio climático puede afectar la seguridad alimentaria son los siguientes:

a) Los desastres naturales y su incidencia sobre las familias en extrema pobreza tienen un impacto del 9 por ciento del total de sus ingresos. (PNUD, 2007)

b) Existe la posibilidad de un acaparamiento del producto, a partir de la no comercialización de maíz y frijol por parte de 
las familias productoras, hay que recordar que en la región centroamericana la producción de estos granos recae sobre pequeños productores, los cuales, al ver que hay escasez de alimentos, tenderán a apropiarse no sólo de lo necesario para su subsistencia, si no a su vez se apropiarán del excedente, propiciando el encarecimiento de maíz y frijol para el resto de la población. En principio, los productores de maíz y frijol podrían guardar su propia reserva, mientras que aquellos que tengan alguna disponibilidad no venderán sus excedentes con la intención de obtener mejoras en el precio de los granos, provocando una especulación en el mercado que a nivel agregado conduciría a un aumento en el precio de los productos.

c) De sostenerse pérdidas de los cultivos por las variabilidades climáticas, la soberanía para producir alimentos se perdería, convirtiendo a El Salvador en un importador neto de granos básicos, reflejando esta situación en una aún más desmejorada balanza comercial.

d) Los índices de desnutrición en las zonas agrícolas y rurales aumentarían, a partir de las limitantes y restricciones que tendrían dichas familias para acceder a los alimentos necesarios.
Es importante aclarar que, el cambio climático es un hecho irrefutable y muy poco puede hacerse ya para mitigarse. Por lo tanto y de cara a este desafío lo único que le queda a un país como El Salvador es buscar las medidas de adaptación que reduzcan la vulnerabilidad de sus habitantes ante los embates de los fenómenos climáticos.

\subsection{Medidas de adaptación y reduc- ción de la vulnerabilidad ante las consecuencias del cambio climático sobre la seguridad alimentaria}

Los mecanismos desarrollados para contrarrestar los efectos negativos del cambio climático descansan sobre los pilares de la mitigación, adaptación y reducción de la vulnerabilidad. La más o menos efectividad de dichas herramientas responde a situaciones y condiciones muy propias del país en el que se implementen, aunque el objetivo que persigan sea el mismo: contrarrestar el cambio climático.

La vulnerabilidad en El Salvador se da por causas sociales, económicas y ambientales que corresponden a procesos de desarrollo urbanístico no controlados, prácticas inadecuadas de cultivos, acelerada deforestación, mal sistema de transporte, alta dependencia de combustibles fósiles, pobreza y desigualdad de ingreso. Además, el estilo de crecimiento económico mundial ha generado condiciones de vulnerabilidad en la población para enfrentar el aumento en la frecuencia de los fenómenos climáticos. Dos de los 
sectores más vulnerables a dichas alteraciones son el sector agrícola y la población rural del país. El primero, por la existencia de malas prácticas agrícolas y la tala indiscriminada de árboles; y el segundo, debido a los bajos niveles de ingresos y la carencia de servicios públicos que garanticen la seguridad de la población rural.

La vulnerabilidad del sector agrícola respecto al Cambio climático conduce a situaciones de mayor riesgo. En muchos casos, los efectos de los fenómenos climáticos se traducen en la reducción de tierras disponibles para cultivos o directamente en reducciones del volumen de producción de alimentos. Por lo tanto, los embates de los fenómenos climáticos acrecientan la vulnerabilidad del país. Sin embargo, las amenazas naturales no necesariamente deben convertirse en desastres y esto puede evitarse con la creación de instrumentos y un marco institucional que garantice la ejecución de los primeros. Partiendo de este supuesto, las acciones encaminadas al control del cambio climático deben estar enfocadas a dos de los tres pilares de acción: Medidas de adaptación y medidas de reducción de la vulnerabilidad.

\subsubsection{Medidas de adaptación para el sector agrícola ${ }^{11}$}

\subsubsection{Medidas de infraestructura}

Las medidas estructurales se refieren a la construcción de infraestructura que permita reducir la vulnerabilidad del país, entre estas medidas se tienen (MARN, 2007):

a) Construcción de canales y desagües en las zonas susceptibles a inundaciones.

b) Construcción de bordas que permitan retener las crecidas de los ríos y el océano.

c) Construcción de estructuras que protejan contra las inundaciones en la zona costera y en la cuenca alta de los ríos

d) Diseño de estructuras que permitan la implementación de distritos de riego y drenaje.

\subsubsection{Medidas no estructurales ${ }^{12}$}

a) Gestiones estatales y ciudadanas para el correcto uso del suelo y manejo de cuencas hidrográficas importantes y zonas costeras vulnerables a inundaciones como las descritas en el mapa 2.1 .

b) Planificación y organización conjunta entre Gobiernos locales y el Estado. Reforestación de cuencas hidrográficas y de otras regiones a través de criterios técnicos en relación a las condiciones biofísicas y agroclimáticas de cada región

c) Implementación de Sistemas de Información Geográfica Satelital (GIS)

d) Programas que incrementen las áreas de siembra de maíz y frijol, ordenado y planificado, con la meta de duplicar la producción de forma gradual, 
que incluya crédito y un seguro que respalde a todos aquellos pequeños y medianos agricultores, ante cualquier fenómeno o crisis que pueda presentarse y afecte sus cultivos.

e) Maximización del uso del suelo actualmente dedicado a granos básicos a través de inversión en tecnología y asistencia técnica bajo mecanismos eficientes público-privados (concursos con metas de rendimiento definidas Ejemplo: $80 \mathrm{qq} / \mathrm{Mz}$.)

\subsubsection{Medidas agronómicas ${ }^{13}$}

Los cambios en el uso de suelo, tales como la deforestación o el aumento de la desertificación, han mostrado alterar el clima a nivel nacional.

Es por ello que para el caso de El Salvador la propuesta de reforestar corresponde a una situación en la que todos ganan pues:

- Se captura $\mathrm{CO}_{2}$

- Se propicia mayor humedad en el suelo y posiblemente más Iluvia

- Se recuperan los bosques del país

- Se protegen las cuencas de los ríos

- Se protege la capa freática ${ }^{14}$ del país, garantizando el correcto abastecimiento de agua.

Es imprescindible considerar como medida de adaptación, la implementación de esquemas de reordenamiento territorial, con esto se puede controlar mejor el uso del suelo, así como disminuir la vulnerabilidad de las poblaciones expuestas a fenómenos hídricos y meteorológicos que se deriven del Cambio climático.

Otro aspecto de vital relevancia para disminuir la vulnerabilidad en los sistemas agrícolas es tomar medidas que permitan la correcta toma de decisiones y acciones preventivas, entre algunas de esas medidas tenemos:

a) Control de plagas a través de mecanismos integrales que permitan obtener rendimientos óptimos sin contaminar el ambiente y los suelos.

b) Manejo integral del suelo en las épocas de post-cosecha.

c) Utilización de variedades de plantas resistentes a sequía y salinidad

d) Cambios en las fechas de siembra, implementación de sistemas mecánicos de riego y modificación en el uso de los suelos.

e) Diversificación de cultivos, orientada a obtener cosechas que permitan reducir los riesgos alimentarios.

f) Implantar programas de capacitación y asistencia, orientados a la consecución de una agricultura más eficiente y tecnificada.

g) Modificación de las técnicas de preparación del suelo 
h) Reducir la erosión de los suelos, especialmente en las laderas.

i) Aumento de cobertura vegetal en los suelos de El Salvador. .

j) Conceder autonomía y refuerzo presupuestario al Sistema $\mathrm{Na}$ cional de Estudios Territoriales (SNET), con el objetivo de facilitar las medidas que permitan adaptaciones paulatinas, y la salvaguarda de vidas y bienes materiales ante repentinos y drásticos cambios en las condiciones climatológicas.

k) Reactivación del Centro Nacional de Tecnología Agropecuaria (CENTA)

I) Establecer programas gubernamentales que se encarguen de vigilar la seguridad alimentaria en El Salvador.

m) Promover inversiones agrícolas, de infraestructura y servicios.

n) Promover la implementación de un programa estatal de Seguros y Reaseguros para las cosechas

o) Fomentar la investigación científica

p) Establecimiento de medidas económicas que incentiven y protejan la producción de granos básicos, así como también de prácticas económicas orientadas a reducir las emisiones de GEI y la vulnerabilidad a los fenómenos climáticos en El Salvador.

q) Promoción de una de agricultura sostenible r) Sustentada en la ecología y en la preservación de la biodiversidad y los recursos naturales.

s) Crear leyes e instituciones que promuevan la seguridad y suficiencia alimentarias como ejes transversales para el Estado salvadoreño.

Finalmente, es importante analizar las ventajas y desventajas que pueden presentar algunas de las medidas de adaptación y reducción de la vulnerabilidad. En primer lugar se tiene la maximización del uso del suelo actualmente dedicado a granos básicos a través de inversión en tecnología y asistencia técnica bajo mecanismos eficientes público-privados. Esta medida presenta las siguientes ventajas: permite disminuir los costos, mejora la rentabilidad del productor, genera más oferta y promueve la integración de los entes públicos directamente con las necesidades privadas. Por otra parte, esta medida presenta algunas desventajas como: el alto costo y el hecho de que los resultados no se visualizarían en el corto plazo.

Otra medida que se plantea interesante es un programa gubernamental de cobertura de precios de maíz en bolsa para mayoristas, que permita asegurar abastecimiento periódico que puede ser comercializado a los mayoristas. Las ventajas que se pueden encontrar en esta medida son las siguientes: permite fijar precio ante posibles alzas futuras, además, permite enviar una 
señal al mercado al garantizar el abastecimiento de maíz. La implementación de este tipo de medidas requiere una fuerte vigilancia por parte del Estado con el objetivo de prevenir transacciones amañadas o riegos financieros.

Algunas medidas ya implementadas como la entrega de semilla mejorada por parte del gobierno plantean como reto, evitar la creación de una dependencia por parte de los productores. Además es importante recalcar que todas las medidas propuestas para mitigar y reducir la vulnerabilidad del país frente al cambio climático deben ser analizadas de forma integral de forma tal que, respondan a las realidades sociales y económicas del país.

\section{Conclusiones}

En este trabajo se ha analizado cómo el cambio climático a partir de las alteraciones naturales, puede aumentar más la vulnerabilidad del acceso de alimentos a las familias

\section{Bibliografía}

Ayala M., 2006. El mecanismo de desarrollo limpio: Acciones a nivel nacional. [En línea]. Disponible en: http://www.marn. gob.sv/uploaded/content/category/1003585536.ppt\#282,1, Diapositiva 1. Presentación realizada por el Ministerio de Medioambiente y Recursos salvadoreñas. Si bien es cierto, que El Salvador ocupa el primer lugar a nivel centroamericano en cuestiones de rendimientos de cultivo de maíz, y que los rendimientos de cultivo de frijol han tendido a incrementarse los últimos años, es necesario que se implementen cambios estructurales que se encuentran asociados al fenómeno de seguridad alimentaria en El Salvador, como una mejor distribución del ingreso, para garantizar una mayor cobertura de la canasta básica a la población que reside en las zonas rurales, las cuales se ven más afectadas.

Como también, un cambio de la estructura productiva de la economía para que el sector agrícola ya no se muestre como un sector estéril y cuente con los utensilios necesarios para desarrollar los cultivos (maíz y frijol), con procesos de producción más organizados y tecnificados, lo que garantizaría alcanzar una mayor productividad y cubrir la capacidad de tierras cultivadas por estos granos.

Naturales MARN. (Consultado el 15 de mayo de 2008)

CENTA, 2008. Boletín No 2 del programa de granos básicos del Centro Nacional de Tecnología Agropecuaria y Forestal del Ministerio de Agricultura y Ganadería de El Salvador. Variedad de frijol. Disponible en http://www.centa.gob.sv/ documentos/frutales/boletines/ 
frijol\%20.pdf. (Consultado el 6 de Agosto de 2008)

DIGESTYC, 2006 Dirección General de Estadísticas y Censos. [En línea] El Salvador, disponible en: http://www.digestyc.gob.sv/publicaciones/EHPM2006/2005/ INDICADORESHOGARES/ CUADRO2006.pdf [Accesado el día 6 de agosto de 2008]

Greenpeace 2006: ¿Qué es el protocolo de Kyoto? Disponible en http://archivo.greenpeace.org/ Clima/Prokioto.htm

Hernández, 2008. Aspectos metodológicos sobre la determinación de la dieta básica promedio (DBP) y la canasta básica alimentaria (CBA). Dirección General de Estadística y Censos. Disponible en: http://www. eclac.cl/deype/mecovi/docs/ TALLER13/13.pdf (Consultado 28 de mayo de 2008

IICA, 2008 Instituto Interamericano de Cooperación para la Agricultura. Mapeo de las cadenas agroalimentarias de maíz blanco y frijol en Centroamérica. [En línea], disponible en: http:// www.iica.int

IPCC 2007. Climate Change 2007: Synthesis Report. Disponible en línea en http://www.ipcc.ch/ pdf/assessment-report/ar4/syr/ ar4_syr.pdf (Consultado 7 de mayo de 2008)
IPCC, 2008. "About IPCC" Disponible en: http://www.ipcc.ch/ about/index.htm. Revisado el 20 de mayo de 2008.

MARN, 1998. "Inventario nacional de gases de efecto invernadero. Año de referencia: 1994". Ismael Sánchez (coord.) Ministerio del Medio Ambiente y Recursos Naturales.

MARN, 2000. Primera comunicación nacional sobre el cambio climático. Ministerio de Medio Ambiente y Recursos Naturales. Disponible en: http://www. marn.gob.sv/uploaded/content/ category/1084153856.pdf (Consultado 15 Mayo de 2008)

MARN, 2007. "Escenarios de referencia de la zona costera" contenido en la "Primera comunicación nacional sobre el cambio climático". Publicada por el Ministerio de Medio Ambiente y Recursos Naturales Disponible en: http://www. marn.gob.sv/uploaded/content/ category/1261232128.pdf. Revisado el 28 de Agosto de 2008.

Martínez, Julia Evelyn. 2006. Apuntes de clase. Cátedra: "Historia del análisis económico".

Muñoz, Arely 2008. "Busca EI Salvador elevar cosecha de granos básicos ante crisis". Disponible en: http://www. metrolatinousa.com/article. cfm?articlelD=35447. (Consultado el 1 de agosto de 2008) 
OEI 2008. "Cambio climático: una innegable y preocupante realidad". Disponible en: http:// www.oei.es/decada/accion 17. htm (Consultado el 09 de Junio de 2008)

OIT, 1970 C131 Convenio sobre la fijación de salarios mínimos 1970 [En línea] disponible en: http://www.ilo.org/ilolex/cgi-lex/ convds.pl?C131 [ Accesado el 6 de agosto de 2008]

ONU, 1992. "Convención Marco de las Naciones Unidas sobre el Cambio climático". Documentos de la ONU. Disponible en: http://unfccc.int/resource/docs/ convkp/convsp.pdf. Revisado el 4 de marzo de 2008.

PESA, 2002. Programa Especial para la Seguridad Alimentaria. Seguridad Alimentaria y Nutricional: Conceptos básicos. Disponible en: http://www.pesacentroamerica.org/biblioteca/

NOTAS

1 Por ejemplo, de acuerdo a la Organización Latinoamericana de Energía (OLADE), el precio de un kilovatio/hora generado mediante la utilización de petróleo cuesta aproximadamente US $\$$ 0.1164, mientras que un kilovatio/hora generado mediante energía solar cuesta alrededor de US\$ 0.61 .

2 Los sectores económicos que el Panel Intergubernamental sobre Cambio Climático (IPCC, por sus siglas en inglés) utiliza para contabilizar la emisión de GEI se dividen en conceptos\%20pdf.pdf (Consultado el 9 de Junio de 2008)

PNUD, 2007. Informe sobre desarrollo humano 2007-2008. La lucha contra el cambio climático: solidaridad para un mundo dividido. Disponible en: http://firgoa.usc.es/drupal/ node/37986. Revisado el 3 de marzo de 2008.

PNUD, 2008. Informe sobre Desarrollo Humano El Salvador 2007-2008 [En línea] disponible en: http://www.pnud. org.sv/2007/idh/content/ view/25/101/ [Consultado el 16 de julio de 2008]

Vidal Villa, 1996. Economía Mundial, Mc Graw Hill. México.

Villarroel, N. y Ventura, M. 2008. "Sequía afecta cultivos en la zona oriental". Disponible en: http://www.elsalvador.com/noticias/2004/08/25/elpais/pais4. asp. (Consultado el 29 de julio de 2008)

sector energético, sector desechos, sector agrícola, sector de cambio en el uso del suelo y sector de procesos industriales. Además, hay que aclarar que, el sector energético incluye todas las actividades relacionadas con el consumo de combustibles fósiles, como la generación de electricidad, el transporte, además de ciertas industrias, actividades domésticas y agrícolas. Para una mejor revisión de éste sector y de los demás, consultar: "El ABC del Cambio Climático" MARN, 2007, pp. 13 y ss. Disponible en: http:// www.marn.gob.sv 


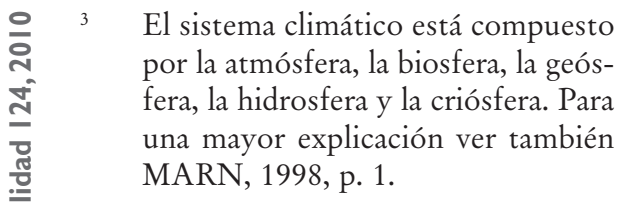

4 En algunas ocasiones se utiliza el término de suficiencia alimentaria como sinónimo de seguridad alimentaria, ya que la disponibilidad de alimentos locales es un indicador tanto de la seguridad alimentaria cómo de la suficiencia.

5 No existe un rendimiento natural propiamente dicho, ya que la mayor parte de semillas que se siembran en el país han sido mejoradas. Ello significa que a través de la intervención humana se han logrado obtener diferentes variedades de semillas con diversos niveles de rendimientos.

6 Elaboración propia.

$7 \quad$ La época de primera comprende los meses de mayo y junio, específicamente cuando inicia el período de lluvias, en esta primera época de siembra las áreas cultivadas son pequeñas, debido al riesgo de cosechar con lluvias. La siembra de postrera que se lleva a cabo en agosto, ya se pueden sembrar extensiones grandes, además se obtiene un grano de mejor calidad, con menor incidencia de plagas y enfermedades. Apante (diciembre), es la época propia de siembra en el litoral Atlántico de Honduras, en el Norte de Guatemala (Petén) y en el centro de Nicaragua.

8 Proceso tecnificado, utilizado en los cultivos de maíz en grandes extensiones de tierra, uso de semilla mejorada con aplicación a agroquímicos y fertilizantes. Proceso semitecni- ficado, utilizado en extensiones de tierra relativamente grandes bajo la alternancia de maquinaria agrícola y métodos tradicionales para el cultivo de maíz, no necesariamente se utiliza semilla mejorada y el consumo de fertilizantes y agroquímicos es mucho menos que en los procesos tecnificados. El proceso de semilla mejorada consiste en la siembra de granos alterados genéticamente. En El Salvador, el MAG está impulsando campanas de entrega de semilla mejorada de frijol y maíz.

\section{Clasificación del Banco Mundial}

Se ha supuesto que el trabajador rural adquiere la canasta básica rural a partir de la premisa que se le imposibilita geográficamente el traslado continuo a las urbes para adquirir los alimentos.

11 La información que se presenta en este apartado ha sido extraída del documento "Escenarios de Referencia de la Zona Costera” contenido en la "Primera comunicación nacional sobre el cambio climático", publicada por el Ministerio de Medio Ambiente y Recursos Naturales (MARN, 2007)

Ibid.

13 El siguiente apartado proviene de la información de los grupos de trabajo realizados por el Banco Interamericano de Desarrollo (BID, 2008)

14 Es la primera capa de agua subterránea que se encuentra al realizar una perforación en el suelo, de forma más rigurosa, la capa freática es: la capa superior de agua libre que llena completamente todos los espacios de un material suelto y granuloso. 